\title{
OPTIMIZING BEEF CATTLE PERFORMANCE USING RUMEN-PROTECTED LYSINE SUPPLEMENTATION IN DIETS BALANCED FOR PREDICTED AMINO ACID AND EFFECTIVE ENERGY REQUIREMENT
}

\author{
A Thesis \\ presented to \\ the Faculty of the Graduate School \\ at the University of Missouri-Columbia
}

In Partial Fulfillment

of the Requirements for the Degree

Master of Science

by

JACQUELYN PRESTEGAARD

Dr. Monty S. Kerley, Thesis Advisor

JULY 2017 
The undersigned, appointed by the dean of the Graduate School, have examined the thesis entitled:

OPTIMIZING BEEF CATTLE PERFORMANCE USING RUMEN-PROTECTED LYSINE SUPPLEMENTATION IN DIETS BALANCED FOR PREDICTED AMINO ACID AND EFFECTIVE ENERGY REQUIREMENT

presented by Jacquelyn Prestegaard a candidate for the degree of Master of Science, and hereby certify that, in their opinion, it is worthy of acceptance.

Dr. Monty S. Kerley

Dr. Allison Meyer

Dr. Harley Naumann 


\section{ACKNOWLEDGEMENTS}

First and foremost, I would like to thank Dr. Kerley for giving me the opportunity to study Ruminant Nutrition at Mizzou - I nearly did not reach out to Ruminant Nutrition programs for fear that no one would take a chance on me, but he did. I have learned more about science, communication, organization and working with others during the last two years than I did throughout all of my previous education. Thanks to him, I stumbled upon this niche of amino acid nutrition research that I never knew would spark my continued interest.

Thank you to my committee members, Dr. Meyer and Dr. Naumann, for taking the time to constructively criticize my work. Special thanks to Dr. Meyer for taking extra time to answer questions I had about experiments or data, looking through seminar slides, and even bringing nutrition lab students together for Journal Club. Support and input from professionals like yourselves are some of the most important assets provided to young, developing scientists.

I am forever in debt to my colleagues - particularly Ann Landers, who is one of the most patient people with whom I've ever had the opportunity to work. I taught myself a great deal during my Master's, but lab safety, techniques, and analyses are learned much better (and safer) through doing. Following protocol on an analysis you've never ran isn't like reading a recipe for a cake you've never made - especially when your ingredients call for flammable, corrosive materials. So many thanks to Ann, who provided answers to countless questions, meticulously scanned and corrected my data mess-ups, and most importantly provided emotional support and reassurance throughout the last few years.

There is a reason I jokingly call Mariana Masiero "mom" - being the eldest graduate student in the Kerley lab, she is constantly sought out by all of us young'uns for scientific and life advice. She never hesitates to offer help to others even when she is drowning in work herself. She 
gave me morale, confidence and friendship, which I value more than the piece of paper I will receive after my time at Mizzou is complete.

I am also forever grateful for the fellow graduate students in the Kerley, Meyer, and Sexten labs who always jumped to help with weigh days, lab work or graveyard shifts during my metabolism study: Blake McDonald, Cooper Martin, Natalie Duncan, Jill Larson, Nick Mertz and Dylan Hamlin. A great group dynamic is what makes work enjoyable, and I feel extremely lucky to have had that here! Thank you as well to the rest of my fellow graduate student friends throughout the department - there are too many to name, which attests to the quality of character we have in Mizzou Animal Science! I also cannot go without thanking our undergraduate students - Jaynee Purdom, Maddie Grant and Connor Locke - who spent endless hours with a Wiley mill or a scale thanks to me, and still managed to smile and say hi to me every day.

I also extend an enormous thank you to the farm managers, Kenneth Ladyman and Luke Barnett, who took care of my feedlot steers and answered any request or question I had throughout my trials. And to Terry, who provided quality early-morning feed truck conversation and always made sure my steers didn't go hungry.

To Bain Wilson, a seasoned graduate student and now academic professional - thank you so much for your endless support. You're the reason why I'm here - "Why don't you check out Mizzou?" were the words you said to me during my senior-year graduate school hunt. Your love and encouragement kept me strong throughout these two tough years apart!

Last but not least, thank you to my family - my Mom and Brad, Dad and Beth, and Grandma and Grandpa especially. You are the most important people in my life, and the only people who truly shared my enthusiasm when the Cubs won the World Series... while I was stuck here in stinkin' Missouri! 


\section{TABLE OF CONTENTS}

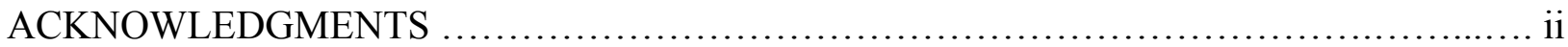

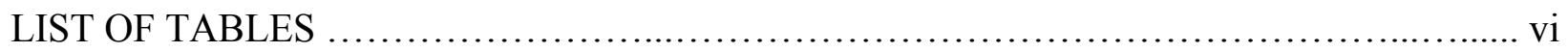

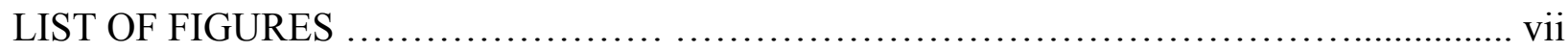

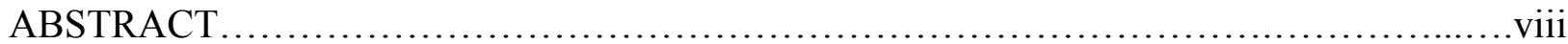

CHAPTER 1

REVIEW OF

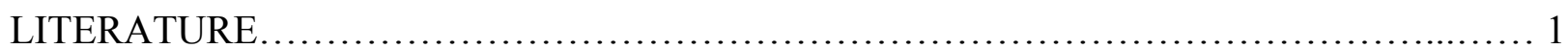

FEED SOURCES OF NITROGEN AND AMINO ACIDS IN RUMINANTS .............. 2

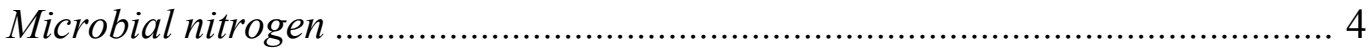

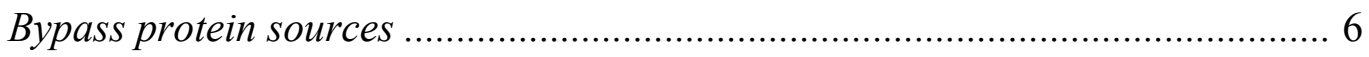

FORUMULATING FOR LIMITING AA IN RUMINANT DIETS ........................... 6

Current estimations of AA requirements in cattle ............................................ 6

Optimizing ruminant diet formulation and predicted intake ..............................8

CONFOUNDING FACTORS OF PREDICTED AA USAGE .................................. 9

Local regulation of AA uptake .................................................................... 9

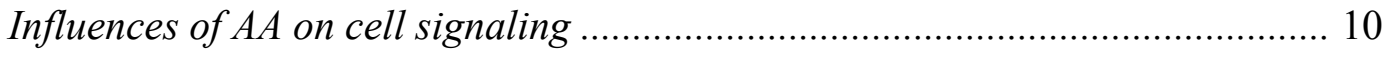

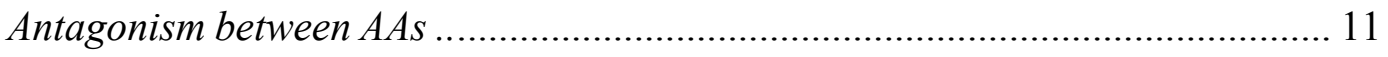

EVALUATION OF ENCAPSULATED AMINO ACID USE IN RUMINANT DIETS ...12

Effects on growing and finishing steer performance ...................................... 12

Effects on lactation performance ................................................................ 16

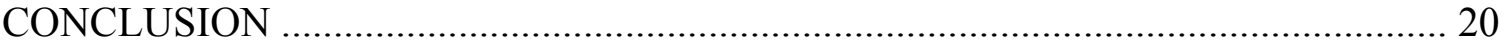

\section{CHAPTER 2}

IN VITRO AND IN VIVO RESPONSES TO DIETARY INCLUSION OF RUMENPROTECTED SOYBEAN MEAL AND ENCAPSULATED LYSINE SOURCES ................ 23

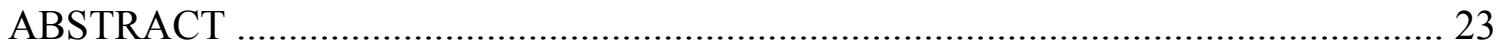

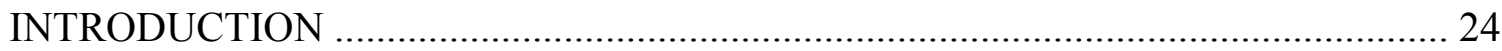

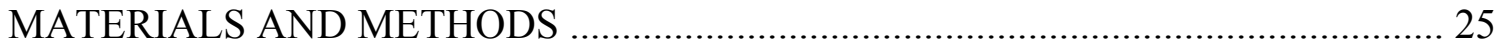

Continuous culture experimental design and sample collection ....................... 25 
Laboratory analysis of continuous culture samples ....................................... 27

In vitro dry matter disappearance study ...................................................... 28

Plasma Lys concentrations in response to RPLys ........................................... 29

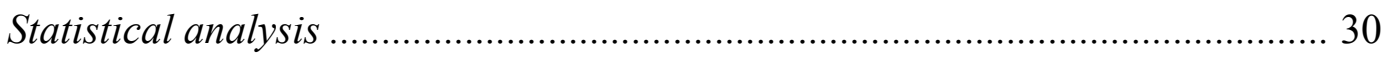

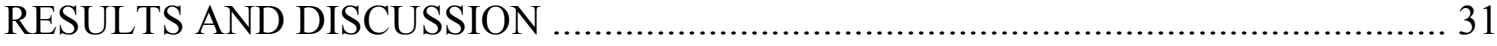

Nitrogen and Lys degradation in continuous culture ................................... 31

Fermentation characteristics in continuous culture ...................................... 32

DM disappearance in DAISY ${ }^{I I}$ incubator .......................................................... 34

Plasma Lys concentrations of steers fed encapsulated Lys ............................. 35

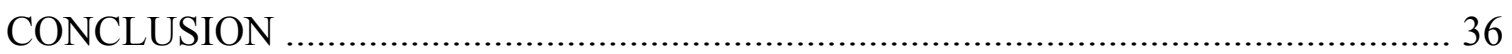

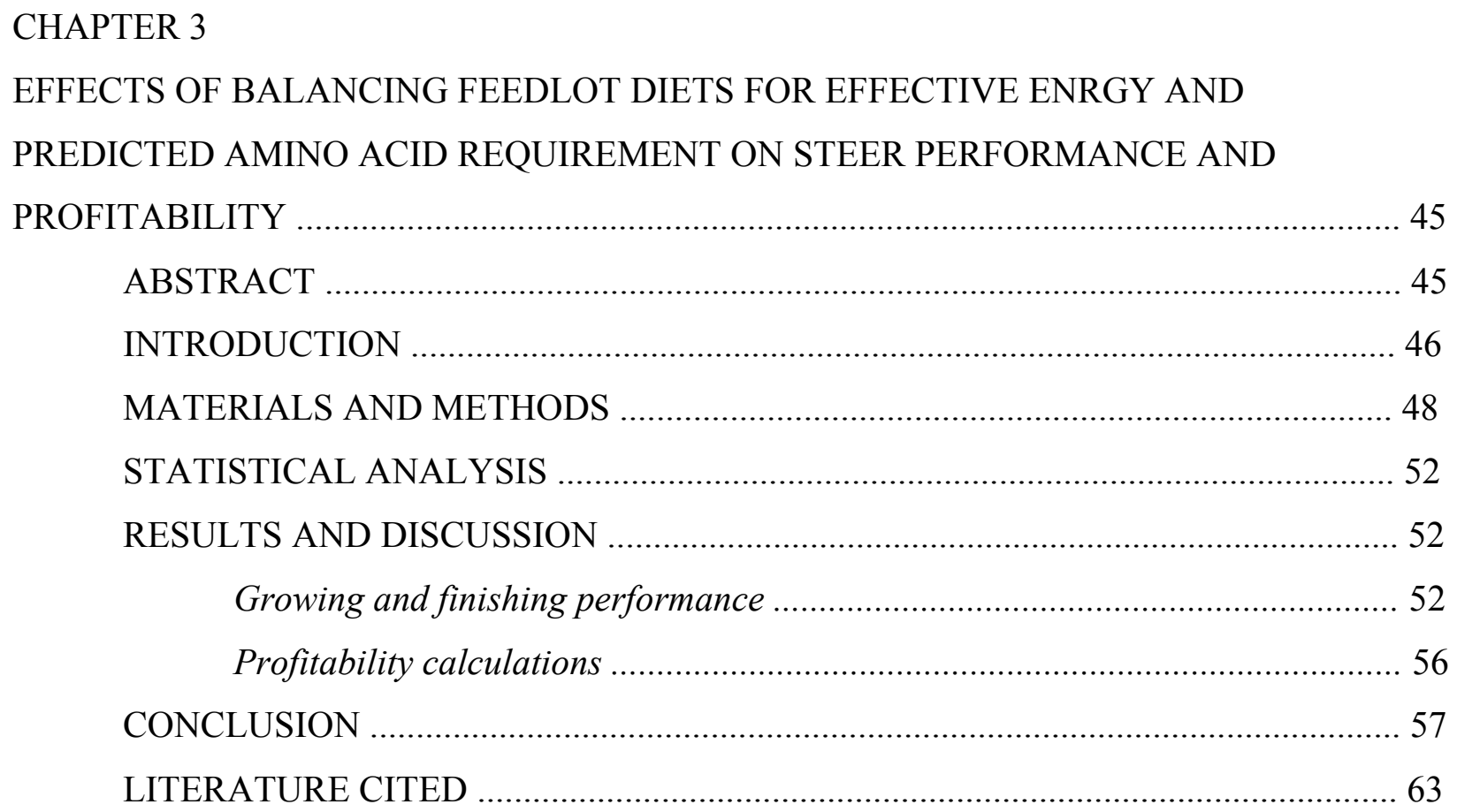




\section{LIST OF TABLES}

TABLE

2.1. INGREDIENT AND CHEMICAL COMPOSITION OF CONTINUOUS CULTURE DIETS 38

2.2. VFA, AMMONIA CONCENTRATION AND PH AT 0 AND 4 H POST-

FEEDING 39

2.3. EFFICIENCY AND PARTITIONING OF NITROGEN AND LYS IN CONTINUOUS CULTURE FERMENTERS

2.4. IN VITRO CP (\%DM) DEGRADATION OF HIGH-RUP FEEDSTUFFS IN DAISY ${ }^{\mathrm{II}}$ INCUBATOR 41

2.5. INGREDIENT AND CHEMICAL COMPOSITION OF DIETS FED TO CANNULATED STEERS

3.2. EFFECTS OF RUMEN-PROTECTED LYSINE SUPPLEMENTATION ON GROWING THROUGH EARLY FINISHING STEER PERFORMANCE 60

3.3. EFFECTS OF RUMEN-PROTECTED LYSINE SUPPLEMENTATION ON EARLY FINISHING THROUGH LATE FINISHING STEER PERFORMANCE 61 


\section{LIST OF FIGURES}

FIGURE

2.1. DM DEGRADATION OF 5 DIFFERENT FEEDSTUFFS IN BATCH CULTURE

2.2. EFFECT OF RUMEN-PROTECTED LYS SUPPLEMENTATION ON CANNULATED STEER PLASMA LYS CONCENTRATIONS AT 4, 8 AND $12 \mathrm{H}$

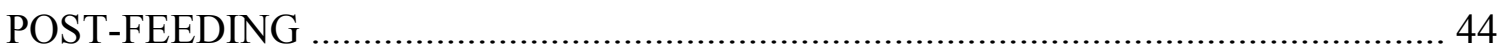

3.1. KAPLAN-MEIER SURVIVABILITY PLOT REPRESENTING PERCENTAGE OF STEERS REMAINING PROFITABLE AFTER 179 DAYS ......................................... 62 


\title{
OPTIMIZING BEEF CATTLE PERFORMANCE VIA RUMEN-PROTECTED LYSINE SUPPLEMENTATION IN DIETS BALANCED FOR PREDICTED AMINO ACID AND EFFECTIVE ENERGY REQUIREMENT
}

Jacquelyn Prestegaard

Dr. Monty Kerley, Thesis Supervisor

\begin{abstract}
The objectives of these experiments were to determine the bypass value of rumen-protected lysine and performance responses of beef cattle fed encapsulated lysine. During experiment 1 singe-flow continuous culture fermenters were fed a Lys-deficient control (CON), a Lys-sufficient diet supplemented with rumen-protected soybean meal (RPSBM; AminoPlus, Ag Processing Inc., Omaha, NE), or a Lys-sufficient diet containing a commercially available rumen-protected Lys product (RPLYS; USA Lysine, Kemin Industries Inc., Des Moines, IA). Results from continuous culture showed greater degradation of RPLYS than RPSBM and CON. During Experiment 2, an in vitro dry matter digestibility study showed DM degradation was $23 \%$ greater for pure USA Lysine than another encapsulated lysine product (AjiPro 2G, Ajinomoto Heartland, Inc., Omaha, NE). The next objective was to test if AjiPro would increase plasma Lys levels in vivo (and therefore indicate its successful ruminal bypass and small intestinal absorption). Experiment 3 involved a 3 x 3 Latin Square study conducted on cannulated crossbred steers fed a combination of rumen-protected soybean meal and two increased levels of the rumen-protected product, where it was fed to meet 100\% (AJ100) and 150\% (AJ150) absorbable AA to effective energy (EE) ratio. Plasma Lys levels were greater when steers were fed diets containing AjiPro in comparison to when they were fed a negative control (NEGCON) which did not contain the product and was deficient in absorbable Lys. From both the in vitro dry matter degradation experiment and the $3 \mathrm{x}$
\end{abstract}


3 Latin Square study, we determined AjiPro to be an effective source of bypass Lys, and consequently used it to conduct a growing through finishing study. During Experiment 4, we evaluated steer performance when fed diets balanced for predicted Lys requirement to EE ratio through its supplementation in several dietary treatments. Control treatments included a negative control (NEGCON) that was deficient in absorbable Lys and contained no rumen-protected products; and a positive control (POSCON) where rumen-protected soybean meal was used to balance absorbable AA to EE ratio. Three additional dietary treatments included similar amounts of rumen-protected soybean meal and incremental amounts of AjiPro formulated to provide $50 \%$ (AJ50), 100\% (AJ100), or 150\% (AJ150) of the absorbable Lys provided by POSCON. Starting on $\mathrm{d} 151$ of the growth study, steers were weighed on 2 consecutive days every $14 \mathrm{~d}$ and assigned a final BW when no longer profitable (defined as when cost of gain exceeded value of gain). Steers remained profitable for greater days for NEGCON, POSCON and AJ100 than AJ150. Steers consuming POSCON had lesser ADG $(\mathrm{kg} / \mathrm{d})$ than all other treatments during the early finishing phase (d 75 to 112). However, steer ADG (kg/d) during late finishing (d 112 to 179) was greater for steers fed diets optimized for Lys requirement (POSCON and AJ100) than all other treatments. Between d 112 to 179 , POSCON had greater G:F than all other treatments but did not differ from AJ100. When encapsulated Lys was under or over-supplemented, finishing steers became less profitable sooner. Feed efficiency increased with use of rumen-protected products during late finishing (d 112 to 179) in diets formulated to meet Lys requirement, but this did not impact overall steer performance from growing through finishing. A more accurate understanding of steer AA requirement and subsequent AA metabolism will allow more precise and effective use of rumenprotected products. 


\section{CHAPTER 1}

\section{REVIEW OF LITERATURE}

\section{INTRODUCTION}

Ruminants are able to digest and metabolize an extensive array of forages and grains. This is almost entirely due to their adaptable ruminal microbial population. These highly specialized microbes digest feed components and convert them into most of the animal's energy needs. In addition to dietary protein, microbes are able to utilize NPN for the synthesis of microbial protein. In fact, depending on a diet's RUP content, microbial protein may account for $50 \%$ to nearly $100 \%$ of an animal's MP requirement (NASEM, 2016). Consequently, optimizing microbial protein synthesis should be a primary goal when developing ruminant diets (Fu et al., 2001).

Ruminal microbes degrade RDP and NPN to ammonia, peptides and AA. As such, 80\% of post-ruminal AA come from microbial protein. During periods of rapid growth or high production, microbial AA are not sufficient enough to meet animal requirements, and post-ruminal AA optimization are needed to ensure efficient performance (Church, 1988).

It is widely accepted that animals require specific essential AA. Still, the current versions of the Nutrient Requirements of Beef Cattle (NASEM, 2016) and Dairy Cattle (NRC, 2001) express protein requirements in terms of MP rather than individual AA. Feeding animals to meet a static MP value may result in $\mathrm{N}$ wastage through feeding of AA in excess of requirement.

The efficiency by which dietary $\mathrm{N}$ is converted to muscle retention is difficult to measure in cattle. However, a recent meta-analysis of 12 individual feeding and $\mathrm{N}$ balance studies in beef cattle (Waldrip et al., 2013) reported mean $\mathrm{N}$ retention [( $\mathrm{N}$ intake - total $\mathrm{N}$ excretion $) \div \mathrm{N}$ intake] of $26.54 \%$ for feedlot cattle consuming typical feedlot diets. Consumption was measured at an 
average of $7.38 \pm 1.36 \mathrm{~kg} \cdot$ animal $^{-1} \cdot \mathrm{d}^{-1}$, and $14.4 \pm 3.09 \% \mathrm{CP}$. For 26 million feedlot cattle in 2016 with an average of 140 days on feed (USDA-ERS, 2017) this equates to nearly 455,000 metric tons of $\mathrm{N}$ wasted to the environment to feeder cattle annually.

Nitrogen waste by livestock not only represents an environmental cost, but an economical cost to the producer because protein is normally the most expensive feed fraction in ruminant diets (Russell et al., 1992). Reducing dietary CP while optimizing diets for AA should increase N efficiency, and consequently reduce monetary and environmental $\mathrm{N}$ waste. An example of this has been calculated for dairy cattle, where a decrease of $2 \% \mathrm{CP}$ in diets has the potential to increase $\mathrm{N}$ efficiency to $>30 \%$, reduce $\mathrm{N}$ losses by 92,000 metric tons/yr and use 543,000 fewer hectares of land to grow soybeans (Haque et al., 2012; Apelo et al., 2014b). High-RUP feedstuffs and/or bypass AA resistant to microbial degradation have been used in an attempt to decrease dietary $\mathrm{CP}$ content and meet AA requirement at no cost (or even at benefit) to animal production.

This review outlines successes and limitations of research attempts to increase post-ruminal AA supply. An overview of microbial $\mathrm{N}$ requirements and usage, and feed sources of RUP (particularly rumen-protected AA) is explained. Current attempts to quantify ruminant AA requirements, confounding factors of predicted AA usage and proposals for formulating diets for optimum AA to energy ratio is also discussed. Finally, literature surrounding both growing and lactating animal responses to supplementary rumen-protected AA is reviewed.

\section{FEED SOURCES OF NITROGEN AND AMINO ACIDS IN RUMINANTS}

\section{Microbial Nitrogen}

The ability to thrive without a dependable source of dietary protein is one of the most notable characteristics of ruminants. This is due to the microbial population within the rumen, 
which synthesizes protein using dietary N, NPN and recycled N from the urea cycle (Lapierre and Lobley, 2001). Pre-gastric microbial fermentation is what separates ruminants from monogastrics. Further, optimizing ruminant nutrition is also optimizing rumen microbiome nutrition. Rumen microbes degrade feedstuffs into products for their own growth, releasing volatile fatty acids (VFA) as end products. These VFA, which are absorbed by the rumen wall, are ruminants' primary source of energy. This is in contrast to monogastrics which rely primarily on absorbed monosaccharides as an energy source.

Rumen degradable protein and NPN are converted to microbial protein, which has a similar AA profile to that of the animal. Consequently, microbial protein is a quality protein source used by the animal when microbes pass into the lower digestive tract. As such, bacterial $\mathrm{N}$ supply is important to consider when determining post-ruminal AA delivery. The NRC provides an approximate value of the AA composition (\%) of bacterial cell-wall and non-cell wall protein (NASEM, 2016; Roman-Garcia et al., 2016). If the amount of post-ruminal microbial N delivery is known, those values may consequently be used to estimate post-ruminal microbial AA delivery. Rumen microflora have a requirement for $\mathrm{N}$ in the form of peptides, $\mathrm{AA}$ or $\mathrm{NH}_{3}$ (Russell et al., 1992). Microbial requirement for $\mathrm{N}$ can be completely fulfilled by urea, $\mathrm{NH}_{3}$ and crossfeeding of AA within bacterial cell walls (Virtanen, 1966). However, microbial growth improves when AA or peptides replace ammonia or urea as the primary source of N. Additionally, some groups of bacteria use AA as their main energy and carbon source and deaminate AA at greater rates than others (Wallace, 1996).

Although rumen microflora can flourish without dietary $\mathrm{CP}$, peptides and free AA may stimulate growth and yield of microorganisms than urea or ammonia alone (Russell et al., 1992). This is partially dependent on dietary fermentation rate and occurs mostly for microorganisms 
growing on rapidly fermentable energy sources. However, peptides and AA do not necessarily stimulate microbial growth in the presence of slowly-degrading fiber. Russell et al (1992) indicated that structural carbohydrate (SC) fermenters only require ammonia as their $\mathrm{N}$ source while nonstructural carbohydrate (NSC) fermenters benefit from AA or peptides.

Total bacterial flow is summarized by the Cornell Net Carbohydrate and Protein System (CNCPS) as the sum of NSC-fermenting bacteria plus SC-fermenting bacteria; these microbes are composed of $10 \% \mathrm{~N}(62.5 \% \mathrm{CP})$ however only $50-70 \%$ of this $\mathrm{N}$ is available to the animal in the form of AA. The remaining $\mathrm{N}$ is bound in cell wall structures and nucleic acids (Russell et al., 1992). Further, $\mathrm{SC}$-fermenting bacteria require all of their $\mathrm{N}_{\text {as }} \mathrm{NH}_{3}$, and $\mathrm{NSC}$-fermenters meet up to $2 / 3$ of their $\mathrm{N}$ requirement with peptides. As a result, high-grain diets foster the growth of NSC fermenters, which will degrade more dietary $\mathrm{CP}$ than SC fermenters.

The current Beef NASEM model also describes microbial RDP requirement as being equal to microbial protein synthesis, although it recognizes the efficiency of converting RDP to microbial protein is less than $100 \%$ (2016). Microbial yield, and subsequently microbial protein is optimized when rumen degradable $\mathrm{N}$ requirement is balanced with rumen degradable peptide supply (Brooks et al., 2012).

\section{Bypass Protein Sources}

Rumen undegradable protein (RUP), or bypass protein, is the fraction of protein that is not degraded by ruminal microbes. Bypass protein avoids microbial degradation for a number of reasons, such as having a chemical composition, particle density and/or particle size that can't be degraded by ruminal microbes. A combination of these factors may also contribute to greater ruminal passage rate that does not allow microbes enough time to degrade the feed fraction. For 
decades, interest has existed to develop high-RUP feedstuffs to increase post-ruminal AA flow to the duodenum. Products developed to achieve this goal include rumen-protected soybean meal (RPSBM) and encapsulated AA. However, have revealed that the post-ruminal flow of essential AA from such products is inconsistent (Ipharraguerre and Clark, 2005).

Most soybean meal (SBM) in the United States goes through hexane-based solventextraction (Do et al., 2014). However, multiple treatments exist to increase the RUP of traditional solvent-extracted SBM. The expeller process involves mechanical pressing, which extracts oil from the soybeans and generates heat, resulting in an increased proportion of RUP. Another method involves heating SBM to at least $200{ }^{\circ} \mathrm{C}$, where the sugars in a feedstuff condense with AA, preventing AA degradation by microbes (Van Soest, 1994; Heitritter et al., 2006). Care must be taken not to overheat the feedstuff, as some AA (particularly Lys) are highly susceptible to heat damage via the Maillard reaction. Compared to other AA, heat-damaged lysine is poorly utilized by the animal (Mao et al., 1993; Wu and Papas, 1997; Vaga et al., 2016).

Various RPSBM products may use a combination of treatments. For example, AminoPlus (Ag Processing, Inc., Omaha, NE) combines heated, high-protein SBM with soyhulls as a source of sugars for non-enzymatic browning (DeGroot et al., 2007). A meta-analysis of nitrogen flow to the small intestine and dairy cow performance revealed that treated SBM provided an increase in milk production $(2.75 \%)$ in cows compared to non-treated SBM, perhaps due to greater cow DMI (Ipharraguerre and Clark, 2005).

Encapsulated AA products consist of a purified core of a single AA, such as Lys or Met, surrounded by a protective coating. The purified AA are typically developed industrially via massscale bacterial fermentation. For example, L-glutamate and L-lysine are primarily produced by fermentation of carbohydrates by Corynebacterium glutamicum (Kiefer et al., 2002). Conversely, 
Met is synthesized via chemical means; successful protection from rumen degradation is achieved through chemically differentiating a Met hydroxy analog (2-hydroxy-4-methylthio butanoic acid) or through physical encapsulation of DL-Met (Willke, 2014; Zanton et al., 2014).

The coating of encapsulated products, which can be made from plant proteins, lipids, polysaccharides or synthetic polymers, should allow the product to pass through the rumen without being degraded by microbes (Blaine, 2014). As a result, the protective coating should lose its integrity when exposed to the low $\mathrm{pH}$ of the abomasum, leaving the purified AA to be absorbed by the small intestine.

\section{FORMULATING FOR LIMITING AA IN RUMINANT DIETS}

\section{Current estimations of $A A$ requirements in cattle}

Of the 10 essential AA, Lys and Met have most often been identified as the most limiting AA for both dairy and beef animals. Forage is typically lacking in Met, rendering it a limiting factor in high-forage diets; corn is relatively low in Lys, rendering it a limiting factor in feedlot diets where corn is often the primary ingredient. Arginine and histidine have been identified as limiting in some cases as well, sometimes due to antagonistic effects between other AA (Ludden and Kerley, 1997; Kim et al., 1999; Ball et al., 2007).

Amino acid requirement varies by individual animal according to life stage, sex and production potential. Requirement also increases in response to pathogen exposure and inflammation (Waggoner et al., 2009). Traditional studies to determine AA requirements are based upon composition of gain, or $\mathrm{N}$ retention/intestinal AA flow after post-ruminal dosage of a specific AA (Klemesrud, 1998). A hallmark study by Richardson and Hatfield (1978) was among the first to identify limiting AA in growing cattle. The authors recognized the importance of optimizing 
both animal and microbial AA requirements. Nitrogen retention and plasma AA concentration were used as indicators of first, second and third-limiting AA of microbial protein in eight abomasally-cannulated steers infused with Lys, Met, Trp and Thr. They determined that Met, Lys and Thr were the first, second and third limiting AA in forage-fed cattle, respectively.

The Dairy NRC (2001) defines requirements for Lys and Met as a percent of MP. They conclude that Lys must comprise $7.2 \%$ of MP and Met must comprise $2.4 \%$ of MP to meet maintenance and milk protein synthesis requirements. Schwab et al (2003) suggested milk protein concentration was optimized when digestible Lys and Met were 6.8 and 2.3\% of MP in flow to the duodenum, respectively. They suggested formulating diets for a Lys:Met ratio (of MP) of 3:1 as it is difficult to meet exact post-ruminal percentages of optimization.

The model Levels 1 and 2 of previous Beef NRC updates $(1996,2000)$ did provide means to estimate the quantity and proportion of AA required by the animal as well as those supplied by the diet. However, their requirements are based on the composition of muscle and whole emptybody contents. Their values for the first two limiting AA, Met and Lys are 2.0 and $6.4 \mathrm{~g} / 100 \mathrm{~g}$ empty body weight, respectively. While this provides some important information about animal AA requirement rather than an overall MP requirement, it is a very limited scope that does not account for co-limiting AA, various production situations and more. Further, the most recent update to the Beef NRC (now called NASEM) removed AA composition of common feedstuffs which was originally listed in previous printed editions (2016). This creates a further obstacle for dietary formulation based on AA requirements of beef cattle. 


\section{Optimizing ruminant diet formulation and predicted intake}

The 2016 edition of the Beef NRC utilizes the MP system to meet cattle protein requirements. However, it recognizes that requirements would be more accurate if expressed on an AA basis, and that more specific information is needed on AA supply from RUP and ruminal microbes (NASEM, 2016).

The most widely used prediction of energy needed for maintenance, growth or lactation requirements is the NE system. The flow of NE begins when ingested energy (GE) is converted to DE after subtraction of fecal energy. Digestible energy is subsequently converted to ME after removal of gaseous energy and urinary energy. The animal's NE is derived from ME after the subtraction of heat increment (HI; the energy cost of eating or rumination).

The NE system does describe the process of energy division for maintenance, tissue accretion and heat. However, it does not account for the different energy efficiencies that exist for protein and lipid accretion. The effective energy (EE) system differs from the NE system in its prediction of how energy is partitioned for growth. Rather than using ME as a whole unit, EE splits ME required for growth into separate functions that account for protein and lipid accretion (Emmans, 1994).

While AA requirements are determined by a variety of factors including life stage, sex, production potential and breed type, individual AA requirement is most dependent upon an animal's energy intake. Increased energy intake results in increased growth or milk production potential, and consequently, AA requirement. To maximize efficiency, it is necessary to balance absorbable AA supply with energy intake. Researchers at the University of Missouri suggest diets balanced for AA:EE are more accurate in predicting energy intake than balancing for NE alone, and that NE may actually over-predict energy requirement by more than $20 \%$ (Kerley, 2016). If 
the diet is not balanced for limiting AA, the animal may overconsume energy until its AA requirements are met.

\section{CONFOUNDING FACTORS OF PREDICTED AA USAGE}

The theory of limiting AA assumes that protein synthesis rate is defined by deficient AA relative to respective animal requirement. This theory likely oversimplifies more complex biological mechanisms occurring within the animal. Additive and independent effects of AA supply may be at play at the cellular level.

\section{Mammary regulation of AA uptake}

Body tissues with high AA usage, such as the mammary gland, can adjust extraction efficiency of AA to maintain adequate local nutrient supply. Despite abomasal infusions of casein plus branched chain AA, lactating cows treated with hyperinsulinemic-euglycemic clamps had drastically reduced AA concentrations in the blood (Mackle et al., 2000). Interestingly, the treatment group maintained similar milk protein yields to the control group, both of which were not MP- or ME-challenged. The mammary gland appeared to support increased milk protein yields via increased mammary blood flow, extraction efficiency of AA and glucose uptake. Mammary regulation also appeared to occur in similar study during which graded removal of Lys from an intravenously-infused AA mixture linearly decreased mammary Lys uptake (Guo et al., 2017). The authors attributed milk protein depression to elevated blood glucose and glucagon levels. In contrast, individual removal of AA from an intravenously infused AA mixture did not change the respective mammary AA uptake from lactating goats fed a diet meeting only MP requirements (Ying et al., 2013). Regulation of AA uptake by mammary and other tissues may be constantly 
adjusted depending on the animal's circulating blood metabolites, and overall energy and AA balance.

\section{Influences of AA on cell signaling}

Mechanistic target of rapamycin (mTOR) is a kinase that integrates input from upstream pathways such as those from insulin, growth factors and AA. It is a central regulator of mammalian metabolism which senses cellular nutrient and energy levels. Mechanistic target of rapamycin is a core component of 2 distinct protein complexes, mTOR complex 1 (mTORC1) and mTOR complex 2 (mTORC2). Mechanistic target of rapamycin complex 1 activation is particularly important in protein synthesis and cell growth, as its activation is required for myofibrillar protein synthesis and skeletal muscle hypertrophy. It also promotes insulin receptor activation.

Mechanistic target of rapamycin complex 1 responds to AA supply (especially Leucine). Due to its role in protein synthesis, the role of mTORC1 has been studied in cattle. These studies have mostly been limited to dairy cattle, however a study by Gingras et al (2007) quantified mTOR upregulation in six crossbred steers. Skeletal muscle insulin insensitivity occurs as animals age, decreasing the ability of skeletal muscle to use AA for growth. Long-chain omega-3 polyunsaturated fatty acids (LCn-3PUFA), which are known to improve insulin-mediated glucose metabolism, were abomasally infused in the form of fish oil. Higher activation of mTOR pathways in in LCn-3PUFA steers was observed at certain AKT target sites (via increased phosphorylation at Ser2448, Thr389 and 4E-BP1 Ser65). The authors concluded LCn-3PUFA steers had greater sensitivity to insulin-regulated AA and glucose disposal in skeletal muscle. More sensitive insulinsignaling occurred in the skeletal muscle of fish oil-fed steers, promoting initiation of mRNA translation and protein synthesis with concurrent reduction in whole-body AA oxidation. This 
increased the net availability of AA to support anabolism. Although evaluating steer performance was not a main objective of the study, fish oil-fed steers had statistically lesser DMI than controls and numerically greater G:F. In summary, sufficient AA supply (especially Leu for this process) may be critical to insulin sensitivity, and therefore efficient growth, in animals whose growth curves may be plateauing.

\section{Antagonism between AAs}

Reduced utilization of an AA may be due to interactions at the metabolic and/or absorptive level. A review in the Journal of Nutrition (Ball et al., 2007) outlined the well-documented antagonistic effects between Lys and Arg in monogastrics. While the exact mechanism behind competition of these AA is not well understood, interference is reported to cause reduction of growth rates in animals due to reduced intake as well as other effects on metabolism and utilization of the antagonized AA. In the case of an AA antagonism, negative effects can only be reversed by supplementing the diet with the AA that is being antagonized, which may not be the same as the limiting AA in the diet. For example, if Met is limiting in a diet, Lys may still be antagonizing Arg in the same diet; therefore, Arg may need to be added to alleviate the competition. Lys and Arg share transporters such as CAT-1 and may compete for intestinal absorption. Some researchers suggest absorptive interactions are at play when plasma AA concentrations do not reflect dietary levels of respective AA (Berge et al., 1999). However, because plasma AA concentrations are transitory and reliant upon feed intake, sampling time and other metabolic factors, other researchers are not confident that interactions at sites of absorption are the primary cause of Lys/Arg antagonism (Ball et al., 2007). 


\section{EVALUATION OF ENCAPSULATED AMINO ACID USE IN RUMINANT DIETS}

Attempts to rumen-protect purified AA within a matrix have been underway since the late 1960s. One of the earliest products was composed of $20 \%$ DL-methionine within a tristearin (a triglycerol) film, which yielded mixed results on ruminal degradation and animal performance in sheep, dairy and beef trials, likely due to poor release in the small intestine (Sibbald et al., 1968; Chalupa, 1975). Chalupa (1975) suggested coating AA with a pH-sensitive material, which is utilized in most encapsulated AAs today. Finding the balance between proper ruminal passage and intestinal release is still a challenge for these products. Literature on the vast array of encapsulated products is widely variable.

\section{Effects on growing and finishing steer performance}

Rumen-protected products are not often utilized in beef diets. In the few beef studies researching rumen-protected AA (RPAA) potential, there are variable, and often negative, results on performance.

Growing steers fed two different types of silage supplemented with both rumen-protected lysine (RPLys) and rumen-protected methionine (RPMet) yielded animals with greater ADG and G:F than non-supplemented steers. Plasma Lys and Met $(\mu \mathrm{g} / \mathrm{mL})$ were also increased, suggesting successful post-ruminal absorption of the RPAA (Veira et al., 1991). While this study in particular only utilized 8 animals/treatment, it is likely that the additional RUP helped alleviate energy and/or AA imbalance due to feeding low-energy grass silage in which the degradability of CP is very high.

Oney et al. (2016) evaluated growth and finishing performance of beef steers consuming common finishing diets supplemented with either RPMet or RPMet + RPLys. No significant 
differences in growth or feed efficiency occurred with RPAA supplementation throughout the duration of the trial. However, all diets were formulated to meet MP requirements, and the authors also mention that is was not clear if individual AA requirements were being met. If so, this may account for the lack of growth response seen when protected AA were fed.

A study conducted by Lancaster et al (2016) also did not yield effects of RPAA supplementation on beef steer growth performance; further, total plasma AA $(\mu \mathrm{g} / \mathrm{mL})$ were not affected. The trial utilized a common feedlot diet vs RPLys- or urea-supplemented steers. However, the authors did not indicate whether AA requirement was considered for cattle. If Met or another AA was first-limiting and only RPLys was supplemented, this may explain a lack of treatment response. Conversely, the control diet may have been sufficient in all AA, which would also elicit no response in treatment diets. A similar study by Hussein and Berger (1995) evaluated growth and finishing performance of Holstein steers supplemented high-concentrate diets with graded levels of RPMet + RPLys $(0,5,10$ or $15 \mathrm{~g} / \mathrm{d}$ of both) containing CP from SBM and SBM + urea. No performance differences existed between control steers and those supplemented with RPAA, however the researchers believe their control diets were not ultimately limited by Lys or Met, which would explain a lack of response to AA supplementation.

The model Levels 1 and 2 of previous Beef NRC updates $(1996,2000)$ provided means to estimate dietary AA supply relative to animal requirement. However, their requirements are based on the composition of muscle and whole empty-body contents. Several other factors should be used to calculate true AA supply and requirement values including microbial growth/composition, dietary RUP composition, post-ruminal AA digestion and absorption and net flux of absorbed AA into tissue. As a result, the AA requirements estimated by the NRC may be quite variable when in 
a variety of situations. Their values for the first two limiting AA, Met and Lys are 2.0 and 6.4 g/100g empty body weight, respectively.

Klemesrud et al (2000b) formulated diets based on the NRC's estimated requirements for MP and other AA (2.0 Met and 6.4 Lys, \%MP) in several steer growing and finishing studies. In one study, nine treatments containing RPLys and RPMet were formulated to provide incremental levels of lysine from RPLys $(0,1,2,3,4,5,6,8,10$ and $12 \mathrm{~g} / \mathrm{d})$ or RPMet alone. Researchers reported increased ADG and G:F during the first $56 \mathrm{~d}$ in steers supplemented at 3 and $4 \mathrm{~g} / \mathrm{d}$ of Lys but this improvement was not sustained through the remainder of the feeding period. In another study, steers fed a meat and bone meal + RPMet to provide 6 incremental levels of RPMet $(0,0.45$, $0.9,1.35,3.0$, or $6.0 \mathrm{~g} / \mathrm{d}$ ) had greater ADG compared to steers fed a urea-supplemented control. The advantage in ADG plateaued at $2.9 \mathrm{~g} / \mathrm{d}$ of Met. Plasma Met concentration also plateaued at this dose. In a separate trial, steers fed a corn gluten meal supplement with incremental amounts of rumen-protected lysine $(0,1,2,3,4,5,6,8$ or $10 \mathrm{~g} / \mathrm{d}$ RPLys $)$ yielded improved ADG compared to steers fed a urea-supplemental control, plateauing at $0.9 \mathrm{~g} / \mathrm{d}$ Lys. Plasma Lys concentrations $(\mu \mathrm{g} / \mathrm{mL})$ exhibited a quadratic response, with an initial increase in concentration followed by a decrease (Klemesrud et al., 2000a).

In an earlier growth study $(84 \mathrm{~d})$, the same researchers fed steers a urea-supplemented control, meat and bone meal supplement, meat and bone meal + RPMet, or meat and bone meal + RPMet and Lys. The diets were not based on predicted AA requirements, but rather protein sources were fed to supply $30,40,50$ or $60 \%$ of the supplemental CP with urea supplying the remainder. This resulted in all diets containing a very low amount of CP (10.7\% DM). Steers supplemented with RPMet had greater ADG and G:F than the urea control and meat and bone meal alone. The 
addition of RPLys only improved ADG and G:F in comparison to the urea control, indicating Lys was not limiting in meat and bone meal but Met was (Klemesrud et al., 1997).

The use of RPAA may work independently of growth promoters like $\beta$-agonists in some aspects and synergistically in others. One study evaluated the effect of supplementing crossbred steers with RPMet, RPLys or a combination of the two RPAA across the entire feeding period (134d), where zilpaterol hydrochloride (ZH) was additionally fed for the final $20 \mathrm{~d}$ (Hosford et al., 2015). Cattle supplemented with RPMet + RPLys had greater FBW than steers fed neither ZH or RPAA and tended to have greater FBW than those fed $\mathrm{ZH}$ alone. During the $\mathrm{ZH}$ feeding period, ADG increased in RPMet and RPMet + RPLys steers versus non-supplemented ZH and non-ZH fed steers. Interestingly, no difference in ADG occurred between $\mathrm{ZH}$-fed steers and steers not supplemented with RPAA or ZH at all. Further, G:F and HCW increased in RPAA-supplemented steers versus negative controls. When compared to positive controls, G:F and HCW tended to increase for RPAA-supplemented steers. The benefits of supplementing RPAA to non- or ZH-fed cattle only manifested during the final $20 \mathrm{~d}$. However, their use resulted in an overall improvement in ADG and G:F across the entire $134 \mathrm{~d}$ period with no differences between $\mathrm{ZH}$ and non-ZH steers. The authors suggested that $\mathrm{ZH}$-fed cattle may not have been able to reach their full growth potential without supplementation of first-limiting AA, likely due to an increased requirement via increased lean growth promoted by ZH.

The limited amount of research surrounding RPAA supplementation in growing and finishing cattle reveals inconsistent experimental designs and treatment diet formulation. Variation in production responses may be explained by different $\mathrm{CP}$ sources, as well as the quality and quantity of RUP in the diet; these are highly variable in both growing and lactating animal trials (Ipharraguerre and Clark, 2005). Experiments in which RUP or AA were very clearly deficient did 
reveal positive responses to rumen-protected products (Veira et al., 1991; Klemesrud et al., 1997; Klemesrud et al., 2000a; Klemesrud et al., 2000b), whereas studies in which researchers were uncertain if control animals were AA deficient did not elicit performance responses (Hussein and Berger, 1995; Lancaster et al., 2016; Oney et al., 2016). This further demonstrates the lack of understanding of the true AA requirements of growing cattle. Evaluation of rumen-protected products using diets formulated based on a set $\mathrm{CP}$ or MP requirement are misleading, as these values alone do not account for post-ruminal availability of peptides and AA.

\section{Effects on lactation performance}

Rumen-protected products receive the most attention in lactating dairy cows. Methionine is certainly the most widely-sold RPAA as it is historically considered first-limiting for milk protein synthesis (NRC, 2001). As previously discussed, the two methods of Met protection involve chemically differentiating Met hydroxy analogs (2-hydroxy-4-methylthio butanoic acid) or physical encapsulation of DL-Met (Willke, 2014; Zanton et al., 2014).

The Dairy NRC (2001) defines requirements for Lys and Met as a percent of MP. Using data from 56 experiments in which Met or Lys was infused abomasally, duodenally or fed in protected form, NRC authors concluded that Lys must comprise $7.2 \%$ of MP and Met must comprise $2.4 \%$ of MP to meet maintenance and milk protein synthesis requirements. Re-evaluation

of these recommendations by Schwab et al (2003) indicated maximization of milk protein concentration when digestible Lys and Met were 6.8 and 2.3\% of MP flow to the duodenum, respectively. Schwab et al (2003) suggest meeting a Lys:Met ratio in MP of 3:1 because it is difficult to formulate diets to provide such precise amounts. 
Milk protein concentration (\%) is the most sensitive component to post-ruminal Lys and Met supply, particularly in post-peak lactation cows. Further, the casein fraction of milk protein is most often affected by these two AA (Socha et al., 2008). The Dairy NRC (2001) states that these responses in milk protein are independent of milk yield and that production responses to supplementary Lys and Met are optimized when CP is within a 14-18\% range.

Milk protein yield $(\mathrm{kg} / \mathrm{d})$ responds with greater variation than milk protein concentration (\%). Improved milk protein yield with increased AA supply in early lactation may result from singular or a combination of several factors, such as (1) a direct effect of supplying AA needed for milk protein synthesis; (2) an indirect effect caused by AA influences on cell signaling and regulation of mammary protein synthesis; (3) an increased ability of the mammary gland to synthesize protein (Carder and Weiss, 2017).

A large body of work supports the finding that AA supplementation in low $\mathrm{CP}$ diets improves milk protein percent, however the type and amount of AA supplemented contribute to a myriad of inconsistent results. Responses in milk protein concentration (\%), but not total yield $(\mathrm{kg} / \mathrm{d})$, may indicate metabolism of supplementary AA in non-mammary tissues. Support for this theory is enhanced when plasma AA concentration $(\mu \mathrm{g} / \mathrm{mL})$ also increases in RPAA-supplemented diets.

As an example, milk protein percent in periparturient Holsteins increased in diets with added RPMet formulated to meet a 3:1 Lys:Met ratio in comparison to a Met-deficient control, however, milk protein yield $(\mathrm{kg} / \mathrm{d})$ did not differ (Ordway et al., 2009). This was complimented with increased plasma Met and total sulfur AA ( $\mu \mathrm{g} / \mathrm{mL}$ and $\%$ total $\mathrm{AA})$ in RPMet-supplemented diets. Similar results were reported in a recent study by Giallongo (2016) in which lactating Holsteins were fed MP-deficient diets supplemented with RPMet, RPLys, RPHis or a combination 
of the 3 RPAA. Milk protein concentration (\%) increased with RPLys, RPHis and the 3-RPAA diet. Milk protein yield $(\mathrm{kg} / \mathrm{d})$ was greater for only the three-RPAA diet. Plasma Lys and His $(\mu \mathrm{g} / \mathrm{mL})$ were increased with RPLys and RPHis additions respectively, but plasma Met did not increase with RPMet supplementation; plasma Lys, Met and His $(\mu \mathrm{g} / \mathrm{mL})$ were all increased in the three-RPAA diet. Positive impacts of supplemental AA on factors like milk protein and milk fat concentrations also been shown to sustain from early lactation to mid-lactation in comparison to diets formulated for high MP without supplemental AA. This further emphasizes the need for distinct AA requirements rather than MP requirements (Carder and Weiss, 2017).

Increases in milk protein concentration (\%), total true milk protein and/or plasma AA in diets supplemented with multiple RPAA may reflect a fulfillment of co-limiting AAs in diets supplemented with only one RPAA. As previously mentioned, dairy cows fed MP-deficient diets supplemented with RPMet, RPLys, RPHis or a combination of the three RPAA only yielded increased milk protein concentration (\%) with RPLys and the three-RPAA combination, and milk protein yield $(\mathrm{kg} / \mathrm{d})$ only increased with the three-RPAA diet (Giallongo et al., 2016). Another study by Lee et al (2012) demonstrated an increase in milk protein yield $(\mathrm{kg} / \mathrm{d})$, but not milk protein concentration (\%) in cows supplemented multiple RPAA (a RPLys + RPMet supplement and a RPLys + RPMet + RPHis treatment) in comparison to an MP-deficient diet. Conversely, cows fed MP-deficient diets supplemented with RPMet, RPLys, RPLeu, RPMet + RPLys, RPMet + RPLeu or a combination of the three RPAA showed no response in milk protein concentration (\%) or milk protein yield $(\mathrm{kg} / \mathrm{d})$. In fact, the combination of RPMet + RPLys + RPLeu significantly decreased milk protein $(\mathrm{kg} / \mathrm{d})$ compared to a MP-sufficient positive control with no supplemental RPAA. The authors attribute the lack of response to RPAA to the limitations of using a fixed postabsorptive efficiency of MP for milk protein synthesis rather than using individual AA 
requirements (Apelo et al., 2014a). This may also result in overlooking another limiting AA, inhibiting production performance.

Histidine is an overlooked, potentially limiting AA. This is particularly true in dairy cows fed grass silage-based diets, especially when RUP supply is limited and post-ruminal microbial protein is increased. Several studies even claim His as the most limiting AA in milk production and milk protein synthesis in low-protein, low-RUP, grass-silage based diets (Kim et al., 1999; Rulquin and Pisulewski, 2000). Lee et al (2012) fed lactating cows a diet sufficient in MP, a diet approximately $15 \%$ deficient in MP with no supplemental RPAA, a diet deficient in MP with RP Lys + RP Met, and a diet deficient in MP with RP Lys + RP Met + RP His. The addition of RPLys + RPMet in MP-deficient diets tended to increase DMI but did not significantly increase milk yield. The inclusion of 3 RPAAs (Lys, Met and His) increased DMI to be similar to cows fed diets sufficient in MP and significantly increased milk yield $(\mathrm{kg} / \mathrm{d})$ in comparison to the nonsupplemented diet. Milk protein concentration was not effected by supplemental AA. However, N efficiency $[($ milk protein yield $\div 6.38) \div \mathrm{N}$ intake $)]$ of MP-deficient diets was enhanced. Ruminal bacteria samples were also analyzed for AA content, and His concentration was found to be $27 \%$ less than Met concentration in bacterial protein. Because microbial protein is a highly important source of AA for cattle, this may also indicate His as a limiting AA in high-production settings. The authors hypothesized that improved milk yield was the result of increased DMI with the inclusion of RPAAs. There was a clear benefit of adding RPAA in N efficiency.

The mixed results in milk protein yield and in low-MP diets supplemented with RPAA further illustrate the lack of understanding of ruminant AA requirements. A study that doesn't elicit a response to RPAA in true milk protein yield may likely indicate an imbalance of energy, another limiting AA, or both. The current Dairy NRC assumes a fixed MP milk protein efficiency 
(MPY/MP supply - MP for maintenance) of $67 \%$ for full-grown, non-pregnant cows. However, several studies demonstrate variable efficiencies for converting MP to milk protein (Whitelaw et al., 1986; Hanigan et al., 1998; Apelo et al., 2014a). As suggested by Apelo et al (2014a), using a fixed number for post-absorptive MP efficiency leads to overfeeding of $\mathrm{N}$ and an expectation of greater production responses from lactating cows. Formulating diets to meet individual AA requirements would consequently allow reduction of $\mathrm{CP}$ levels and maximize post-absorptive $\mathrm{N}$ efficiency.

\section{CONCLUSION}

Identifying ruminant AA requirements is challenging due to ruminal degradation of dietary AA and ambiguous microbial AA supply. As such, using dietary AA intake to express subsequent usage by the animal is impractical and inaccurate. Gut AA metabolism is a set of complex interactions that must be understood to successfully meet ruminant AA requirements. Understanding the synchrony between these processes will allow diet formulation that improves efficiency of $\mathrm{N}$ conversion to milk protein in dairy animals and lean muscle in growing animals. This will translate into less $\mathrm{N}$ wastage, which represents both environmental and economic benefits.

Individual AA requirement is most dependent upon an animal's energy intake. Increased energy intake results in increased growth or milk production potential, and consequently, increased AA requirement. To maximize efficiency, it is necessary to balance absorbable AA supply with energy intake. Balancing diets for effective energy (EE) to predicted AA ratio has been shown to be more accurate in predicting intake than NE, as NE may over-predict energy requirement. If the diet is not balanced for limiting AA, the animal may overconsume energy until its AA requirements are met. 
Rumen-protected products represent a potential way to balance AA in growing animal diets. The limited amount of research surrounding RPAA supplementation in growing and finishing cattle reveals inconsistent experimental designs and treatment diet formulation. Evaluation of rumen-protected products using diets formulated with set $\mathrm{CP}$ or MP requirements are often misleading, as these values alone do not account for post-ruminal availability of peptides and AA. Variation in production responses may be explained by different $\mathrm{CP}$ sources, as well as the quality and quantity of RUP in the diet; these are highly variable in both growing and lactating animal trials. When predicted AA requirements of growing cattle are taken into account, using RPAA to balance for optimum AA:EE ratio has the potential to yield desirable production responses.

Lysine is often a limiting AA in grain-based diets, therefore animals consuming highconcentrate diets may need supplemental sources of post-ruminal Lys to meet their full production potential (Richardson and Hatfield, 1978). The objectives of the following experiments were (1) to evaluate post-ruminal appearance and absorption of rumen-protected Lys products, and (2) to evaluate steer performance when fed diets balanced for predicted Lys requirement to EE ratio using rumen-protected Lys. In vitro experiments were conducted to determine the dry matter disappearance of several rumen-protected products over time, as well as their impact on ruminal fermentation characteristics. Plasma Lys concentrations were then measured in cannulated steers fed increasing levels of encapsulated rumen-protected Lys to determine if the product increased post-ruminal Lys absorption. Finally, performance characteristics were evaluated in beef steers fed diets balanced for predicted Lys requirement to effective energy (EE) ratio using rumen-protected Lys. 


\title{
CHAPTER 2
}

\section{IN VITRO AND IN VIVO RESPONSE TO DIETARY INCLUSION OF RUMEN- PROTECTED SOYBEAN MEAL AND ENCAPSULATED LYSINE SOURCES}

\begin{abstract}
Three experiments were conducted to estimate post-ruminal characteristics of several types of bypass AA sources. In Experiment 1, a single-flow, continuous culture system was used to evaluate microbial efficiency (MOEFF), dietary Lys degradability and fermentation characteristics of a bypass soybean meal (AminoPlus; AgProcessing Inc., Omaha, NE) and an encapsulated Lys source (USA Lysine; Kemin Industries Inc., Des Moines, IA). Inoculated fermenters were randomly assigned to 1 of 3 treatments in 2 consecutive replicates $(n=24)$ : A Lys-deficient basal diet (CON) consisting of corn, soybean meal and corn silage; a Lys-sufficient diet (RPSBM) containing AminoPlus in replacement of soybean meal in the basal diet; and a Lys-sufficient diet (RPLYS) consisting of CON and supplemental USA Lysine. In Experiment 2, an in vitro dry matter digestibility (IVDMD) study was conducted to evaluate disappearance of USA Lysine (RPLU), a second encapsulated Lys source (RPLA; AjiPro 2G, Ajinomoto Heartland, Inc., Omaha, NE) and several high-RUP feedstuffs. During Experiment 3, jugular blood was collected at 4,8 and, 12 h post-feeding from ruminally cannulated crossbred steers consuming a negative control (NEGCON) that was deficient in absorbable Lys and contained no rumen-protected products; a treatment formulated to balance absorbable AA to EE ratio using AminoPlus and AjiPro 3G (AJ100); and a diet balanced to provide 150\% of the absorbable Lys provided by AJ100 via increased AjiPro 3G inclusion (AJ150). In continuous culture, microbial efficiency (MOEFF; g microbial N/kg OM truly digested $)$ tended to be greater $(P=0.08)$ in RPLYS than RPSBM and CON. Bypass dietary Lys $(\mathrm{g} D \mathrm{DM} / \mathrm{d})$ was less $(P<0.01)$ in RPLYS relative to RPSBM and CON.
\end{abstract}


Dietary Lys degradability $(\% \mathrm{DM})$ was greater $(P<0.01)$ for RPLYS relative to RPSBM or CON. However, total effluent Lys $(\mathrm{g} D M / \mathrm{d})$ tended to be greater $(P=0.08)$ for CON and RPSBM than RPLYS. During the IVDMD study, $43.59 \%$ (DM) of RPLU was degraded, whereas $10.05 \%$ of RPLA was degraded by rumen microbes. Finally, steers fed AJ100 and AJ150 had greater $(P<$ 0.10) plasma Lys concentrations than NEGCON. Lesser extent of AjiPro degradation in vitro as well as increased plasma Lys concentration through its supplementation suggest greater ruminal bypass relative to USA Lysine.

\section{INTRODUCTION}

Rumen microbiota digest protein originally fed to the animal to fulfill their own maintenance and growth requirements. Although microbial protein meets a large portion of the animal's AA requirements, RUP must comprise part of the diet for AA requirements to be met for cattle with high levels of production. Because Lys is often the first limiting AA in grain-based diets, care should be taken to ensure animals consuming high-concentrate diets receive an adequate amount of post-ruminal Lys (Richardson and Hatfield, 1978). Feedstuffs such as rumen-protected soybean meal (RPSBM) and encapsulated AA may increase post-ruminal AA flow to the duodenum. However, research surrounding the post-ruminal flow of essential AA from these products yield inconsistencies (Ipharraguerre and Clark, 2005).

Multiple treatments exist to increase the RUP of traditional solvent-extracted soybean meal (SBM). For example, AminoPlus (Ag Processing, Inc., Omaha, NE) combines heated, highprotein SBM with soyhulls as a source of sugars for non-enzymatic browning (DeGroot et al., 2007). Encapsulated AA products consist of a purified core of a single AA, such as Lys or Met, surrounded by a protective coating. The purified AA are typically developed industrially via massscale bacterial fermentation. The coating of encapsulated products, which can be made from plant 
proteins, lipids, polysaccharides or synthetic polymers, should allow the product to pass through the rumen without being degraded by microbes (Blaine, 2014). As a result, the protective coating should lose its integrity when exposed to the low $\mathrm{pH}$ of the abomasum, leaving the purified AA to be absorbed by the small intestine.

We hypothesized that rumen-protected products would increase post-ruminal Lys in vitro in diets formulated to meet microbial RDPep and RDN requirement. We also postulated that inclusion of rumen-protected Lys at or above predicted AA requirement would increase plasma Lys concentrations in vivo. The objective of this experiment was to evaluate MOEFF, Lys digestibility, and other fermentation parameters of both a bypass soybean meal product (RPSBM) and an encapsulated Lys source (RPLYS) in continuous culture. Further, we aimed to compare IVDMD and CP disappearance (\% DM) of two commercial encapsulated Lys sources. Finally, we conducted an in vivo study to evaluate plasma Lys concentrations of steers fed treatments containing rumen-protected Lys.

\section{MATERIALS AND METHODS}

\section{Continuous Culture Experimental Design and Sample Collection}

Twenty-four single-flow continuous culture fermenters were used in a randomized complete block design in 2 separate replicates. Ingredient inclusions were adjusted between treatments in order to provide similar amounts of RDP to supply sufficient peptides and $\mathrm{NH}_{3}$ to meet microbial requirements. Fermenters were randomly assigned to 1 of 3 treatments (Table 1): A Lys-deficient basal diet consisting of corn, SBM, and corn silage (CON); a Lys-sufficient diet containing rumen-protected soybean meal (AminoPlus, AgProcessing Inc, Omaha, NE) in replacement of SBM in the basal diet (RPSBM); and a Lys-sufficient diet consisting of CON 
supplemented with encapsulated Lys (RPLYS; USA Lysine; Kemin Industries Inc., Des Moines, IA). Diet samples were collected and composited at the end of each fermentation run.

Rumen fluid was collected via vacuum-operated pump from 3 ruminally cannulated crossbred steers. Hot water was added to $2 \mathrm{~L}$ thermoses before collection, then dumped prior to harvesting rumen fluid. After rumen fluid was added to the pre-warmed thermoses, a handful of forage mat was added to each container to provide microbes a surface on which to attach. Each thermos was then immediately transported to the laboratory for processing (estimated travel time $10 \mathrm{~min})$.

At the laboratory, rumen fluid was blended (Model 34BL22 Blender, Waring, New Hartford, CT) for 3, 5-sec pulses to detach particle-associated microbes from feed. It was strained through 4 layers of cheesecloth and diluted with McDougall's artificial saliva in a 1:2 dilution of rumen fluid to buffer. Twenty-four polycarbonate vessels (Nalgene, Rochester, NY) were then inoculated with approximately $1,460 \mathrm{~mL}$ of rumen fluid (filled up to the effluent overflow port). Silicone tubes were connected to a $\mathrm{CO}_{2}$ tank which maintained anaerobic conditions. To simulate rumen temperature, 4 water baths (6 fermenters/bath) were maintained at $39^{\circ} \mathrm{C}$ using thermostatically controlled heaters (Fisher Scientific, Pittsburgh, PA). Rumen fluid contents were continuously stirred with magnetic plates. A high buffer capacity solution was continuously infused into fermenters using peristaltic pumps (modification of McDougall's artificial saliva by Slyter (1990); Masterflex model 7250-10, Cole Parmer Instrument Co., Chicago, IL). The buffer contained $470 \mathrm{mg}$ urea-N/L and $250 \mathrm{mg}$ cysteine- $\mathrm{HCl} / \mathrm{L}$. Fermenter dilution rates were held constant at $5.0 \pm 0.47 \% \mathrm{~h}^{-1}$ for all treatments. Effluent cylinders were kept on ice continuously throughout the sampling period. 
Fermenters were fed half the daily ration $(46 \mathrm{~g} \mathrm{DM} / \mathrm{d})$ by hand at $0800 \mathrm{~h}$ and $1700 \mathrm{~h}$. Total incubation time was $7 \mathrm{~d}$ ( $4 \mathrm{~d}$ adaptation and $3 \mathrm{~d}$ sampling). During the sampling period, 2, 5-mL liquid samples were taken from fermenters at 0 and $4 \mathrm{~h}$ after morning feeding and placed in separate $15-\mathrm{mL}$ centrifuge tubes designated for $\mathrm{NH}_{3}$ and VFA analysis. Both samples were acidified using $6 \mathrm{~N} \mathrm{HCl}$, and $16 \mu \mathrm{l}$ of 2-ethylbutyric acid was added to the tube designated for VFA analysis as an internal marker. These 2 samples were then immediately frozen at $20^{\circ} \mathrm{C}$. These samples were composited for each fermenter over the 3-d period for each sampling time. On the

final day of each replicate, effluent was collected into plastic graduated cylinders, composited and frozen at $0700 \mathrm{~h}$ before morning feeding. Effluent volume was recorded daily to monitor dilution rate. Whole fermenter content was collected and frozen on the final day of each replicate and used to measure $\mathrm{DM}, \mathrm{OM}, \mathrm{CP}, \mathrm{NDF}$, and $\mathrm{ADF}$ digestibility, and purine and Lys content. The $\mathrm{pH}$ was recorded immediately before morning feeding and $4 \mathrm{~h}$ after morning feeding using a glasselectrode $\mathrm{pH}$ meter. More detailed descriptions of the continuous culture system, dilution rate control, operation conditions, and sampling procedures are described by Meng et al (1999).

During the first replicate, data for 12 fermenters were unusable due to equipment malfunction; during the second replicate, data for 5 fermenters were not analyzed for the same reason.

\section{Laboratory Analysis of Continuous Culture Samples}

For analysis of purines and microbial Lys, whole fermenter content was thawed in warm water, blended to separate bacteria from feed particles and then centrifuged at $1,000 \mathrm{xg}$ for $10 \mathrm{~min}$ at $4^{\circ} \mathrm{C}$. Supernatant was collected and feed particles were discarded. The liquid was centrifuged again at $1,000 \mathrm{xg}$ for $10 \mathrm{~min}$ at $4^{\circ} \mathrm{C}$. Supernatant was collected and feed particles discarded again. 
The solution was then centrifuged at $27,000 \mathrm{xg}$ for $20 \mathrm{~min}$ at $4^{\circ} \mathrm{C}$. The supernatant was discarded; the resulting pellet was washed with deionized distilled $\mathrm{H}_{2} \mathrm{O}$ and centrifuged once more at 27,000 $\mathrm{x}$ g for $20 \mathrm{~min}$ at $4^{\circ} \mathrm{C}$. The bacteria-containing pellet was added to plastic cups and lyophilized (Genesis 25XL, Virtis, Gardiner, NY), then ground using a mortar and pestle. Whole effluent contents were sub-sampled and divided into three $600 \mathrm{ml}$ plastic containers, lyophilized, and ground using a mortar and pestle.

Dried diet, fermenter, and effluent samples were analyzed for DM (AOAC, 2012a), ash (AOAC, 2012b), and N content (vario Micro Cube, Elementar Americas, Mt Laurel, NJ). To determine microbial efficiency (MOEFF; g microbial N/kg OM truly fermented), fermenter and effluent samples were analyzed for purine content using the procedure of Makkar and Becker (1999). Effluent and diet samples were analyzed for NDF and ADF (ANKOM ${ }^{200}$ Fiber Analyzer, ANKOM Technology, Macedon, NY). A UV/Vis spectrophotometer (Evolution 201, Thermo Scientific, Waltham, MA) was used to measure $\mathrm{NH}_{3}$ concentration $(\mathrm{mM})$ using the procedure outlined by Broderick and Kang (1980). Volatile fatty acid concentration (mM) was analyzed using gas chromatography (Model 3400, Varian, Palo Alto, CA) according to Erwin et al. (1961). Dietary, microbial, and effluent Lys were analyzed by the University of Missouri Experiment Station Chemistry Laboratory according to the AOAC official method 982.30 (AOAC, 2005).

\section{In Vitro Dry Matter Disappearance Study}

To further test the degradation rate of our rumen-protected AA (RPAA) sources, a followup in vitro study was conducted using multiple high-RUP feedstuffs (Fig. 1). Treatments included soybean meal (SBM), AminoPlus (RPSBM), blood meal (BM), USA Lysine (RPLU), and AjiPro 2G (RPLA; Ajinomoto Heartland, Inc., Omaha, NE). Two buffer solutions (Ankom Technology, 
2005) were warmed to $39^{\circ} \mathrm{C}$ before sample bag inoculation. The solutions were mixed in a 5:1 ratio and 1,600 $\mathrm{mL}$ of the mixed buffer was added to each vessel. Sealed vessels were incubated for $20 \mathrm{~min}$ to allow the system to reach $39^{\circ} \mathrm{C}$. Rumen fluid was collected via vacuum-operated pump from 2 ruminally cannulated crossbred steers and prepared as described for the continuous culture section.

The SBM, RPSBM, and BM were ground to $1 \mathrm{~mm}$. The RPLU and RPLA were unground to preserve protection of AA. Approximately $0.50 \mathrm{~g}$ of each feedstuff was sealed in nylon bags and placed in a DAISY ${ }^{\mathrm{II}}$ Incubator (ANKOM Technology, Macedon, NY). Each 2-L vessel ( $\mathrm{n}=$ 4) contained 20 feedstuff sample bags plus 4 blanks. Bags were placed into warmed vessels and removed at assigned times of $0,4,8,12$, and $24 \mathrm{~h}$ post-incubation. When bags were removed, each vessel was immediately flushed with $\mathrm{CO}_{2}$ for at least $30 \mathrm{~s}$, resealed, and returned to the incubator. Upon removal, bags were generously rinsed with cool tap water until water ran clear in to remove microbes. They were then dried at $105^{\circ} \mathrm{C}$ then weighed to calculate DM disappearance. Contents were also analyzed for N disappearance (vario Micro Cube, Elementar Americas, Mt Laurel, NJ).

\section{Plasma Lys Concentrations in Response to RPLys}

The experimental protocol was approved by University of Missouri Animal Care and Use Committee. Three ruminally and duodenally cannulated steers $(939 \pm 31 \mathrm{~kg} \mathrm{BW})$ were used in a 3 x 3 Latin Square study to determine plasma Lys concentrations when fed diets containing rumenprotected Lys (AjiPro 3G, Ajinomoto Heartland, Inc.). Animals were housed in separate, outdoor, dirt-floored pens and had ad libitum access to water.

Over a 14-d period, steers were stepped up from their previous pasture-based diet to the negative control treatment (NEGCON; Table 2.5), which was deficient in absorbable Lys and 
contained no rumen-protected products. After the step-up period, steers were adapted to experimental diets (Table 2.5) over $14 \mathrm{~d}$ and fed at 0700 and 1900. Two additional dietary treatments included similar amounts of rumen-protected SBM (AminoPlus, Ag Processing Inc., Omaha, NE); they included AJ100, which was formulated to balance absorbable AA to EE ratio, and AJ150, which was balanced to provide $150 \%$ of the absorbable Lys provided by AJ100. Diets were mixed in a hand mixer to ensure adequate homogenization of ingredients.

During the last $4 \mathrm{~d}$ of adaptation NEGCON was fed to all steers until each animal would no longer consume feed after a $1 \mathrm{~h}$ time period. The orts, if any, were weighed and stored at $-20^{\circ} \mathrm{C}$. Orts were used to adjust the amount of feed offered the following day to establish a common intake $\% \mathrm{BW}$ DM for each individual. This would be used as the amount fed per animal for the rest of the trial. Consequently, dietary offerings were readjusted according to steer BW that was measured at the beginning of each experimental period. Adaptation to each diet lasted $7 \mathrm{~d}$, and experimental periods lasted $4 \mathrm{~d}$.

Jugular blood samples (approximately $10 \mathrm{~mL}$ each) were collected from steers at 4, 8, and $12 \mathrm{~h}$ post-feeding into $\mathrm{K}_{2}$ EDTA vacutainers (Becton, Dickinson and Company, Franklin Lakes, NJ) for plasma Lys analysis. The samples were kept on ice and immediately transported to the laboratory for processing. Samples were centrifuged at $1500 \mathrm{xg}$ for $30 \mathrm{~min}$ at $4^{\circ} \mathrm{C}$, then plasma was pipetted into $2 \mathrm{ml}$ microcentrifuge tubes. Plasma samples were frozen at $-20^{\circ} \mathrm{C}$ and sent to University of Missouri Experimental Station Chemical Laboratory for total AA analysis (Le Boucher et al., 1997). 


\section{Statistical Analysis}

For continuous culture data, statistical analyses were performed using the GLM procedure of SAS 9.4 (SAS Inst. Inc., Cary, NC). Data were analyzed as a randomized complete block (replicate served as block) with fermenter as experimental unit. To account for unbalanced group sizes between replicates, the Kenward-Rogers adjustment was used to approximate degrees of freedom. When no replicate or treatment*replicate effects occurred, replicate, and interactions were removed from the model and treatment effects were assessed for total of 31 fermenters across both replicates. Fisher's Least Significant Difference (LSD) Test was used to compare pairwise differences between dietary treatments. Treatment results are reported as least square means with significance declared at a $\alpha=0.05$ and tendencies declared at $\alpha=0.10$.

In vitro dry matter disappearance data analysis was performed using PROC MIXED in SAS. Filter bag was used as experimental unit and vessel was fitted as a random effect. Data were analyzed as a completely randomized design. Treatment results are reported as least square means with significance declared at a $\alpha=0.05$ and tendencies declared at $\alpha=0.10$. Pairwise differences between feedstuffs at each individual hour were compared using the PDIFF command.

Plasma Lys analysis was performed using PROC MIXED in SAS using steer as a repeated measure. Steer, treatment, period, hour, period*treatment, and treatment*hour interactions were fitted in the model. No significant effect of hour, period, treatment*period or treatment*hour occurred so they were removed from the model and means across all periods were pooled and analyzed. Reported means were obtained using LSMEANS and pairwise differences between dietary treatments were obtained using the PDIFF statement. 


\section{RESULTS AND DISCUSSION}

\section{Nitrogen and Lys degradation in continuous culture}

Apparent $\mathrm{CP}$, true $\mathrm{CP}$, and $\mathrm{OM}$ digestibility were not affected by treatment (Table 2.3). Total $\mathrm{N}$ flow (g DM/d), non-ammonia $\mathrm{N}$ (NAN; g DM/d), non-ammonia non-microbial $\mathrm{N}$ (NANMN; g DM/d), and microbial N (g DM/d) were also not affected by treatment $(P>0.10$ for all parameters), however $\mathrm{N}$ efficiency ( $\%$ of dietary $\mathrm{N}$ intake converted to microbial $\mathrm{N}$ ) of RPLYS tended to be greater $(P=0.10)$ than both of the other treatments.

Treatment tended $(P=0.08)$ to affect total effluent Lys $(\mathrm{g} / \mathrm{d}$; Table 2.3$)$. Total effluent Lys in RPSBM was greater $(P=0.03)$ than RPLYS, but neither treatment differed from $\mathrm{CON}(P=0.12$ vs RPSBM; $P=0.54$ vs RPLYS). Dietary and microbial Lys in effluent were analyzed to quantify the profile of bypass dietary Lys. Microbial Lys in effluent (g DM/d) was numerically greater for RPLYS (0.27) than CON (0.21) and RPSBM (0.25). Further, dietary Lys in the effluent (g DM/d) was lesser for RPLYS in comparison to both CON $(P<0.01)$ and RPSBM $(P=0.01)$; CON and RPSBM did not differ from each other $(P=0.44)$. This was surprising because fermenters receiving RPLYS were fed 29\% more Lys (g/d) than both CON and RPSBM (Table 2.3). When Lys digestibility (\% dietary Lys degraded in vitro) was calculated, it was greater for RPLYS than RPSBM and CON $(P<0.01$ for both treatments). Lys digestibility was not different between CON and RPSBM $(P=0.49)$.

Microbial efficiency (MOEFF; g N/kg OM truly fermented) was greater for RPLYS vs both CON and RPSBM ( $P=0.05$ vs both treatments); no differences occurred between $\mathrm{CON}$ and RPSBM $(P=0.94)$. Both RPSBM and RPLYS contained bypass AA, so we expected dietary Lys in the effluent to be greater for both RPSBM and RPLYS. However, effluent dietary Lys was significantly less for RPLYS than the other 2 treatments. Instead, the increase of Lys in RPLYS 
may have occurred in microbial Lys in the effluent. An in situ evaluation of a rumen-protected Met product by Berthiaume et al (2000) did not show statistical differences of MOEFF when compared to a control, although there were numerical differences (20.8 for control and 25.3 for RPMet). Additionally, bacterial $\mathrm{N}$ and Met flow ( $\mathrm{g} / \mathrm{kg}$ of DM flow at the duodenum) were greater in their RPMet treatment. Increased bacterial N flow suggests improved microbial synthesis, perhaps stimulated by partial degradation of the RPAA. These results suggested fermenter (ruminal) degradation of USA Lysine, so we conducted an in vitro DM degradation analysis using the DAISY ${ }^{\mathrm{II}}$ incubator to further evaluate the efficacy of our rumen-protected Lys source.

\section{Fermentation characteristics in continuous culture}

Any replicate or replicate*treatment differences were attributed to inevitable variability of rumen fluid collected from animals at different periods of time. As a result, only treatment effects will be discussed.

Total VFA $(\mathrm{mM})$, acetate: propionate ratio, acetate $(\mathrm{mol} / 100 \mathrm{~mol})$ or propionate $(\mathrm{mol} / 100$ mol) were not different $(P>0.05)$ across treatments at either $0 \mathrm{~h}$ or $4 \mathrm{~h}$ post-feeding (Table 2.2). This was not unexpected because all diets were formulated to meet microbial requirements by providing similar amounts of RDP to supply sufficient peptides and $\mathrm{NH}_{3}$. Vazquez-Anon et al (2001) reported no differences in total or individual VFA concentrations in continuous culture diets supplemented with different levels of rumen-protected methionine (RPMet). In a similar continuous culture experiment (Guillaume et al., 1991), analysis of raw vs. extruded soybeans with or without RPMet + RPLys showed no effect on individual or total VFA concentration. Conversely, an in-situ experiment evaluating treated and non-treated SBM yielded lesser total propionate and total VFA molar concentration, and greater acetate concentration for treated SBM; 
however, the SBM was treated with Ca-lignosulfonate rather than heat (Windschitl and Stern, 1988).

Butyrate $(\mathrm{mol} / 100 \mathrm{~mol})$ was greater at both $0 \mathrm{~h}(P=0.01)$ and $4 \mathrm{~h}(P=0.01)$ post-feeding in CON and RPLYS. It did not differ between CON and RPLYS (Table 2.2). This was not expected and difficult to explain, as previously mentioned rumen-protected product in vitro experiments either noted differences in total VFA, acetate, propionate, or no differences in all. Butyrate may play a role in urea $\mathrm{N}$ recycling and may also inhibit propionate use by the liver, particularly in highly fermentable diets (Agarwal et al., 2015). However, this is normally accompanied by increased $\mathrm{NH}_{3}$ concentrations, which was not observed at $0 \mathrm{~h}$ or $4 \mathrm{~h}$ post-feeding. Additionally, OM digestibility was not different between treatments in the present experiment, indicating diets were degraded at similar rates.

As previously mentioned, $\mathrm{NH}_{3}$ concentrations were not different at $0 \mathrm{~h}$ or $4 \mathrm{~h}$ post-feeding $(P=0.97$ and 0.21 , respectively). This suggests our formulation of similar microbial RDPep and RDN balances were balanced correctly, and similar results for $\mathrm{NH}_{3}$ were reported by Brooks (2012) in continuous culture diets formulated for RDPep and RDN.

Fermenter $\mathrm{pH}$ was greater $(P=0.01)$ for RPSBM at $0 \mathrm{~h}$ vs CON. RPLYS $\mathrm{pH}$ tended to differ $(P=0.09)$ from RPSBM at $0 \mathrm{~h}$ (Table 2.2). CON and RPLYS pH did not differ at $0 \mathrm{~h}(P=$ 0.41). At $4 \mathrm{~h}$, RPSBM pH was still greater $(P=0.07)$ than $\mathrm{CON}$, but this was only a tendency. RPLYS had the lowest $\mathrm{pH}$ at $4 \mathrm{~h}$ and was greater $(P=0.02)$ than RPSBM. CON pH at $4 \mathrm{~h}$ did not differ $(P=0.55)$ from RPLYS. The lowest mean $\mathrm{pH}$ in both replicates was 6.4 , which is still above the $\mathrm{pH}$ threshold (6.2) assumed to increase lag time and decrease cell wall digestion (Van Soest, 1994). Some strains of Lys-degrading bacteria are highly sensitive to rumen $\mathrm{pH}$, and have been shown to be inhibited at an acidity as low as 6.1 (Russell, 2006). However, average fermenter $\mathrm{pH}$ 
at 0 and $4 \mathrm{~h}$ was between 6.4-6.7, so the reduction in $\mathrm{pH}$ in RPLYS was not of concern in regards to microbial health.

\section{DM disappearance in DAISYII incubator}

Figure 2.1 depicts degradation rates and IVDMD results from the DAISY ${ }^{\mathrm{II}}$ incubation. A treatment*hour interaction for IVDMD occurred, which was expected. The same occurred for CP (\%DM) degradation. As a result, differences between feedstuffs at each individual hour were evaluated for both variables.

At $0 \mathrm{~h}$, RPLA and RPLU had similar percentages of IVDMD, and together had less DM loss than the other feedstuffs. For BM, RPSBM, and SBM, IVDMD was greater $(P<0.01$ for all $)$ between each other. Removal from vessels at $4,8,12$, and 24 h post-incubation was greater $(P<$ 0.0001) in the order: SBM, RPSBM, RPLU, BM, and RPLA for all time points. Final IVDMD was greater $(P<0.0001)$ for RPLU compared to RPLA.

After $24 \mathrm{~h}$, no more than $10.05 \%$ of either BM or RPLA had been degraded by rumen microbes. This indicated high DM bypass for BM and RPLA, and low DM bypass of RPLU.

More dynamic differences occurred for CP (\%DM) degradation of the feedstuffs. Crude protein degradation differed $(P<0.01$ for all) between all feedstuffs at $0 \mathrm{~h}$, which represents degradation of immediately soluble CP. Degradation of RPSBM was greatest (Table 2.4, $P<0.01$ ), followed by SBM, BM, RPLU, and RPLA. After 4 h, CP degradation (\%DM) still differed $(P<$ 0.01 for all) between all treatments, but the greatest degradation occurred in SBM, followed by RPSBM, RPLU, BM, and RPLA. At 8 h post-incubation, feedstuff CP (\%DM) degradation did not differ between SBM, RPSBM, BM, and RPLU, but all were greater $(P<0.01)$ than RPLA. 
After $24 \mathrm{~h}$, all treatments differed from each other $(P<0.01)$ where SBM had the greatest CP (\%DM) degradation, followed by RPSBM, RPLU, BM, and RPLA.

Interestingly, all CP (\%DM) degradation values for RPLA were negative, which actually indicated $\mathrm{N}$ addition rather than degradation. This may be due to the presence of microbial protein. All filters were rinsed together to remove microbes; so, microbes may have been more firmly attached to RPLA particles. As time progressed, the DM disappearance of RPLA remained fairly static, but $\mathrm{CP}(\% \mathrm{DM})$ of the feedstuff increased. This phenomenon could be observed more extensively by analyzing microbial $\mathrm{N}$ content of AjiPro over time in vitro.

The 2 rumen-protected AA used in this study were also evaluated during a study conducted by Tucker et al (2015). They determined the plasma Lys levels of cows fed three different RPLys products, including USA Lysine and AjiPro 2G. Plasma AA levels can be used to determine bioavailability, and therefore efficacy, of post-ruminal AA. Neither high nor low rates of USA Lysine increased plasma Lys, and its bioavailability was found to be only $38.2 \%$ of AjiPro $2 \mathrm{G}$. Further, contact with feed particles can compromise RPAA product efficacy due to lower $\mathrm{pH}$ of feedstuffs (Ji et al., 2016). Our IVDMD study helped validate that degradation in continuous culture wasn't due to RPAAs being pre-mixed in diets.

\section{Plasma Lysine Concentrations of Steers Fed Encapsulated Lysine}

Plasma Lys concentrations $(\mu \mathrm{mol} / \mathrm{L})$ are represented in Fig 2.2. A treatment effect was observed $(P=0.05)$, where AJ150 resulted in greater plasma Lys concentration than NEGCON $(P$ $=0.02)$ and $\mathrm{AJ} 100(P=0.09)$. No differences occurred between $\mathrm{AJ} 150$ and $\mathrm{AJ} 100(P=0.44)$. No effects were observed for hour $(P=0.15)$, period $(P=0.43)$, treatment*hour interaction $(P=0.72)$ or treatment*period interaction $(P=0.59)$. 
In their study, growing steers fed low quality silage supplemented with both RPMet and RPLys yielded greater ADG and G:F than non-supplemented steers. Plasma Lys and Met concentrations were also increased in supplemented cattle. A series of growth studies conducted by Klemesrud et al (Klemesrud et al., 1997; Klemesrud et al., 2000a; Klemesrud et al., 2000b) evaluated responses of plasma Met and/or Lys concentrations in growing cattle. Steers were fed RPAA in incremental amounts, and plateaus in plasma AA concentration were used as indicators of requirement being fulfilled for that particular AA. Richardson and Hatfield (1978) also used plateaus in plasma AA concentration to determine animal AA requirement via incremental abomasal infusions of AA. Because no pairwise difference occurred between AJ100 and AJ150 regardless of hour, Lys requirement was likely met while steers consumed AJ100. Because both AJ100 and AJ150 resulted in greater plasma Lys concentration than NEGCON, it is likely that NEGCON created a Lys deficiency.

\section{CONCLUSION}

We originally hypothesized that rumen-protected lysine products would increase in vitro effluent Lys flow in diets formulated to meet microbial RDPep and RDN requirement. While MOEFF tended to increase in RPLYS during the continuous culture study, the same did not occur for RPSBM. However, total effluent Lys was lowest for RPLYS compared to the other two treatments. While there was a benefit of using the encapsulated product in RPLYS in regards to microbial and $\mathrm{N}$ efficiency, this trend did not translate to improved post-ruminal Lys supply. The advantage in MOEFF may be a result of numerically increased microbial N flow in RPLYS. The deficit of Lys occurred as a result of lower dietary Lys within the effluent, seemingly due to poor protection of the encapsulated AA. The lower effluent dietary Lys was accompanied by 
numerically increased effluent microbial Lys in RPLYS. Further, DM of our original RPLYS source was degraded $23 \%$ more after $24 \mathrm{~h}$ in the IVDMD study than another encapsulated Lys source on the market. We concluded that USA Lysine did not bypass microbial degradation as anticipated, resulting in increased microbial $\mathrm{N}$ due to a greater supply of AA to the microbial population. While this did increase MOEFF, the product did not provide adequate post-ruminal Lys in comparison to RPSBM or CON. Cannulated steers fed diets to meet or exceed Lys requirements via AjiPro 3G supplementation yielded increased plasma Lys concentrations relative to a Lys-deficient diet, suggesting post-ruminal absorption of the product. The results from these three studies showed AjiPro had greater ruminal bypass than other high-RUP feedstuffs, making it a potentially reliable candidate for animal Lys supplementation in future research. 
Table 2.1. Ingredient and chemical composition of continuous culture diets.

\begin{tabular}{lccc}
\hline & \multicolumn{3}{c}{ Treatment $^{1}$} \\
\cline { 2 - 4 } Item & CON & RPSBM & RPLYS \\
\hline Ingredient, \% DM & & 66.3 & 75.6 \\
$\quad$ Corn, cracked & 75.1 & 23.2 & -- \\
AminoPlus $^{2}$ & -- & -- & 15.7 \\
Soybean Meal & 16.4 & 9.0 & 6.8 \\
Corn Silage & 6.9 & -- & 0.3 \\
USA Lysine & & 0.1 \\
MFP & -- & 0.2 \\
Urea & 0.1 & 0.2 & 1.3 \\
Vitamin Mineral Premix & 5 & 1.3 & \\
Analyzed nutrient content & 0.2 & & 91.4 \\
DM, \% & 1.3 & 91.9 & 17.0 \\
CP, \% DM & & 18.4 & 0.83 \\
Lys, \%DM & 91.4 & 0.78 & \\
\hline
\end{tabular}

${ }^{1} \mathrm{CON}=$ Lys-deficient basal diet; RBSBM = Lys-sufficient diet containing rumen-protected soybean meal (AminoPlus; AgProcessing Inc, Omaha, NE) in replacement of SBM in the basal diet; RPLYS = Lys-sufficient diet consisting of CON supplemented with encapsulated Lys (USA Lysine; Kemin Industries Inc., Des Moines, IA). Ingredient inclusions were adjusted between treatments in order to provide similar amounts of RDP to supply sufficient peptides and $\mathrm{NH}_{3}$ to meet microbial requirements.

${ }^{2}$ AminoPlus (AGP, Omaha, NE) analyzed to contain 47.01 CP (\%DM); 38.0\% RUP; 62.0\% RDP. ${ }^{3}$ USA Lysine (Kemin Industries Inc., Des Moines, IA) predicted to contain $53.6 \%$ Lys-HCl.

${ }^{4}$ MFP (Novus International Inc., St. Charles, MO) predicted to contain 84.0\% 2-hydroxy-4methylthio butanoic acid.

${ }^{5}$ Vitamin Mineral Premix contained 1,814,369 IU/kg of vitamin A; 362,874 IU/kg of vitamin D; and $567 \mathrm{IU} / \mathrm{kg}$ of vitamin E. Contained $24.0 \% \mathrm{Ca} ; 3.0 \% \mathrm{Zn} ; 2.5 \% \mathrm{Fe} ; 2.0 \% \mathrm{Mn} ; 1.0 \% \mathrm{Cu} ; 100$ ppm Se; 500 ppm I; and 100 ppm Co. 
Table 2.3. Efficiency and partitioning of nitrogen and Lys in continuous culture fermenters.

\begin{tabular}{|c|c|c|c|c|c|}
\hline \multirow[b]{2}{*}{ Parameter } & \multicolumn{3}{|c|}{ Treatment $^{1}$} & \multirow[b]{2}{*}{ SEM } & \multirow[b]{2}{*}{$P$} \\
\hline & $\mathrm{CON}$ & RPSBM & RPLYS & & \\
\hline \multicolumn{6}{|l|}{ Nitrogen characteristics, DM } \\
\hline Dietary N intake, g/d & $1.15^{\mathrm{c}}$ & $1.36^{\mathrm{a}}$ & $1.26^{\mathrm{b}}$ & 0.05 & $<0.01$ \\
\hline Apparent CP digested, \% & 28.37 & 32.74 & 30.16 & 2.70 & 0.49 \\
\hline True CP digested, \% & 53.99 & 55.86 & 59.37 & 2.97 & 0.45 \\
\hline $\mathrm{NH}_{3}-\mathrm{N}, \mathrm{mg} / \mathrm{N} / 100 \mathrm{~mL}$ & 16.55 & 18.45 & 16.14 & 1.05 & 0.25 \\
\hline Total N flow, g/d & 1.10 & 1.17 & 1.10 & 0.04 & 0.25 \\
\hline $\mathrm{NAN}^{2}, \mathrm{~g} / \mathrm{d}$ & 0.82 & 0.84 & 0.80 & 0.06 & 0.82 \\
\hline $\mathrm{NANMN}^{3}, \mathrm{~g} / \mathrm{d}$ & 0.43 & 0.44 & 0.36 & 0.05 & 0.40 \\
\hline Microbial $\mathrm{N}$ flow, $\mathrm{g} / \mathrm{d}$ & 0.39 & 0.40 & 0.48 & 0.03 & 0.09 \\
\hline MOEFF $^{4}$ & $17.49^{\mathrm{b}}$ & $17.62^{\mathrm{b}}$ & $21.32^{\mathrm{a}}$ & 1.33 & 0.08 \\
\hline $\mathrm{N}$ efficiency ${ }^{5}, \%$ & $33.85^{\mathrm{b}}$ & $29.94^{\mathrm{b}}$ & $35.80^{\mathrm{a}}$ & 2.02 & 0.10 \\
\hline \multicolumn{6}{|l|}{ Lys characteristics, DM } \\
\hline Dietary Lys intake, g/d & $0.33^{\mathrm{b}}$ & $0.34^{\mathrm{b}}$ & $0.43^{\mathrm{a}}$ & 0.00 & $<0.01$ \\
\hline Total effluent Lys, g/d & $0.34^{\mathrm{ab}}$ & $0.37^{\mathrm{a}}$ & $0.33^{\mathrm{b}}$ & 0.01 & 0.08 \\
\hline Microbial effluent Lys, g/d & 0.21 & 0.25 & 0.27 & 0.02 & 0.13 \\
\hline Dietary effluent Lys, g/d & $0.14^{\mathrm{a}}$ & $0.12^{\mathrm{a}}$ & $0.07^{\mathrm{b}}$ & 0.02 & $<0.01$ \\
\hline Lys digested, $\%^{6}$ & $65.73^{b}$ & $60.15^{\mathrm{b}}$ & $85.84^{\mathrm{a}}$ & 4.57 & $<0.01$ \\
\hline OM digestibility, \% & 51.05 & 52.26 & 52.24 & 2.97 & 0.86 \\
\hline
\end{tabular}

a,b Rows with uncommon superscripts differ $P<0.05$.

${ }^{1} \mathrm{CON}=$ Lys-deficient basal diet consisting of corn, soybean meal (SBM) and corn silage; RBSBM = Lys-sufficient diet containing rumen-protected soybean meal (AminoPlus; AgProcessing Inc., Omaha, NE) in replacement of SBM in the basal diet; RPLYS = Lyssufficient diet consisting of CON supplemented with encapsulated Lys (USA Lysine; Kemin Industries Inc., Des Moines, IA).

${ }^{2}$ Non-ammonia $\mathrm{N}(\mathrm{NAN})$ determined by the formula: $\mathrm{NAN}=$ total $\mathrm{N}$ flow $-\mathrm{NH}_{3} \mathrm{~N}$.

${ }^{3}$ Non-ammonia, non-microbial $\mathrm{N}(\mathrm{NANMN})$ determined by the formula $=\mathrm{NANMN}=\mathrm{NAN}-$ microbial N.

${ }^{4}$ Microbial efficiency $(\mathrm{MOEFF})=\mathrm{g}$ microbial N/kg OM truly digested.

$5 \%$ of dietary $\mathrm{N}$ converted to microbial $\mathrm{N}$.

${ }^{6} \%$ of dietary Lys digested during fermentation. 
Table 2.4. In vitro CP\% degradation of high-RUP feedstuffs in Daisy ${ }^{\text {II }}$ incubator.*

\begin{tabular}{|c|c|c|c|c|c|}
\hline \multirow[b]{2}{*}{ Feedstuff } & \multicolumn{5}{|c|}{ Incubation time, $\mathrm{h}$} \\
\hline & 0 & 4 & 8 & 12 & 24 \\
\hline $\mathrm{SBM}^{1}$ & $17.34^{b}$ & $31.53^{\mathrm{a}}$ & $29.27^{\mathrm{a}}$ & $41.64^{\mathrm{a}}$ & $58.00^{\mathrm{a}}$ \\
\hline RPSBM $^{2}$ & $23.71^{\mathrm{a}}$ & $23.77^{\mathrm{b}}$ & $28.54^{\mathrm{a}}$ & $27.55^{\mathrm{b}}$ & $37.98^{\mathrm{b}}$ \\
\hline Blood Meal $^{3}$ & $9.51^{\mathrm{c}}$ & $7.88^{\mathrm{d}}$ & $24.04^{\mathrm{a}}$ & $13.04^{\mathrm{d}}$ & $13.97^{\circ}$ \\
\hline $\mathrm{RPLU}^{4}$ & $1.45^{\mathrm{d}}$ & $15.98^{\mathrm{c}}$ & $24.81^{\mathrm{a}}$ & $18.53^{\mathrm{c}}$ & $34.21^{\mathrm{b}}$ \\
\hline RPLA $^{5}$ & $-8.95^{\mathrm{e}}$ & $-69.49^{\mathrm{e}}$ & $-71.84^{b}$ & $-80.06^{\mathrm{e}}$ & -96.93 \\
\hline SEM & 1.41 & 2.14 & 1.29 & 1.58 & 2.25 \\
\hline \multicolumn{6}{|c|}{$\mathrm{a}, \mathrm{b}, \mathrm{c}, \mathrm{d}, \mathrm{e}$ Means in columns without common superscripts differ $(P<0.01)}$. \\
\hline \multicolumn{6}{|c|}{${ }^{1} \mathrm{SBM}=$ Soybean meal. } \\
\hline \multicolumn{6}{|c|}{${ }^{2}$ RPSBM = AminoPlus; AgProcessing Inc., Omaha, NE } \\
\hline \multicolumn{6}{|c|}{${ }^{3} \mathrm{BM}=$ Blood meal. } \\
\hline \multicolumn{6}{|c|}{${ }_{5}^{4} \mathrm{RPLU}=$ USA Lysine; Kemin Industries Inc., Des Moines, IA. } \\
\hline \multicolumn{6}{|c|}{${ }^{5}$ RPLA = AjiPro 2G; Ajinomoto, Heartland Inc., Chicago, IL. } \\
\hline${ }^{*}$ Daisy ${ }^{\mathrm{II}}$ incul & $\mathrm{OM} \mathrm{Tec}$ & gy, Mac & & & \\
\hline
\end{tabular}


Table 2.5. Ingredient and chemical composition of diets fed to cannulated steers.

\begin{tabular}{lccc}
\hline & \multicolumn{3}{c}{ Treatment $^{1}$} \\
\cline { 2 - 4 } Item & NEGCON & AJ100 & AJ150 \\
\hline Ingredient, \%DM & & & \\
Corn & 53.3 & 53.0 & 53.0 \\
DDGS $^{2}$ & 33.4 & 25.9 & 25.7 \\
AminoPlus $^{3}$ & -- & 7.60 & 7.60 \\
Oatlage & 10.6 & 10.6 & 10.6 \\
Lime & 1.53 & 1.53 & 1.53 \\
Salt & 0.45 & 0.45 & 0.45 \\
Vitamin E & 0.13 & 0.13 & 0.13 \\
MgO & 0.26 & 0.26 & 0.26 \\
Vitamin ADE & 0.06 & 0.06 & 0.06 \\
Rumensin & 0.03 & 0.03 & 0.03 \\
Vitamin Mineral Premix & 6 & 0.19 & 0.19 \\
AjiPro 3G & 0.19 & 0.26 & 0.51 \\
Nutrient Content & -- & & \\
DM, \% & & 74.0 & 73.0 \\
CP, \% DM & 73.0 & 18.2 & 18.3 \\
AA:EE Ratio* & 16.8 & 1.00 & 1.00 \\
Lys Requirement, \%** & 1.48 & 100.0 & 116.0 \\
\hline
\end{tabular}

${ }^{1}$ NEGCON $=$ deficient in absorbable Lys and contained no rumen-protected products; AJ100 $=$ formulated to balance absorbable AA to EE ratio using AminoPlus and AjiPro 3G; AJ150 = balanced to provide $150 \%$ of the absorbable Lys provided by AJ100 via increased AjiPro 3G inclusion.

${ }^{2}$ DDGS $=$ dried distiller's grains with solubles.

${ }^{3}$ AminoPlus (AGP, Omaha, NE) analyzed to contain 47.01 (\%DM); 38.0\% RUP; 62.0\% RDP. ${ }^{4}$ ADE Nutra Mix contained 1,814,369 IU/kg vitamin A, 362,874 IU/kg vitamin $\mathrm{D}_{3}$, and 227 IU/kg vitamin E; Nutra Blend, LLC, Neosho, MO.

${ }^{5}$ Rumensin 90; Elanco Animal Health, Greenfield, IN.

${ }^{6}$ Vitamin Mineral Premix contained 1,814,369 IU $/ \mathrm{kg}$ of vitamin A; 362,874 IU $/ \mathrm{kg}$ of vitamin $\mathrm{D}$; and $567 \mathrm{IU} / \mathrm{kg}$ of vitamin E. Contained $24.0 \% \mathrm{Ca} ; 3.0 \% \mathrm{Zn} ; 2.5 \% \mathrm{Fe} ; 2.0 \% \mathrm{Mn} ; 1.0 \% \mathrm{Cu}$; $100 \mathrm{ppm}$ Se; $500 \mathrm{ppm} \mathrm{I}$; and 100 ppm Co.

${ }^{7}$ AjiPro 3G (Ajinomoto Heartland Inc., Chicago, IL) predicted to contain 50.0\% Lys-HCl.

*AA:EE = absorbable amino acid to effective energy ratio. Approximated through diet formulation.

${ }^{* *}$ Lysine requirement approximated through diet formulation. 


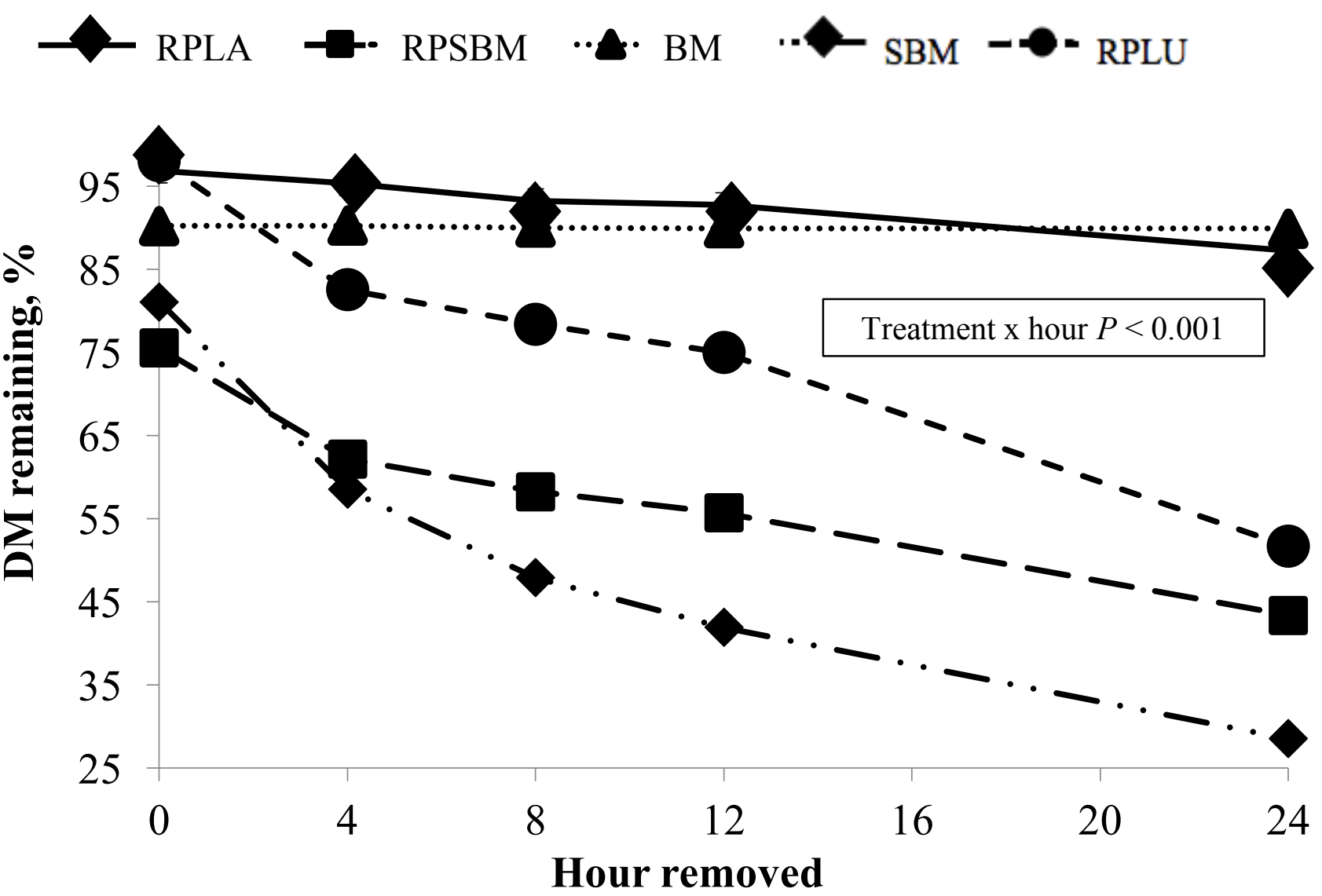

Figure 2.1. DM degradation of 5 different feedstuffs in batch culture (treatment $x$ hour interaction, $P<0.001$, SEM = 1.6). RPLA = AjiPro 3G (Ajinomoto Heartland Inc., Chicago, IL); RPSBM = AminoPlus (Ag Processing Inc., Omaha, NE); BM = blood meal; $\mathbf{S B M}=$ soybean meal; RPLU = USA Lysine (Kemin Industries, Des Moines, IA). 


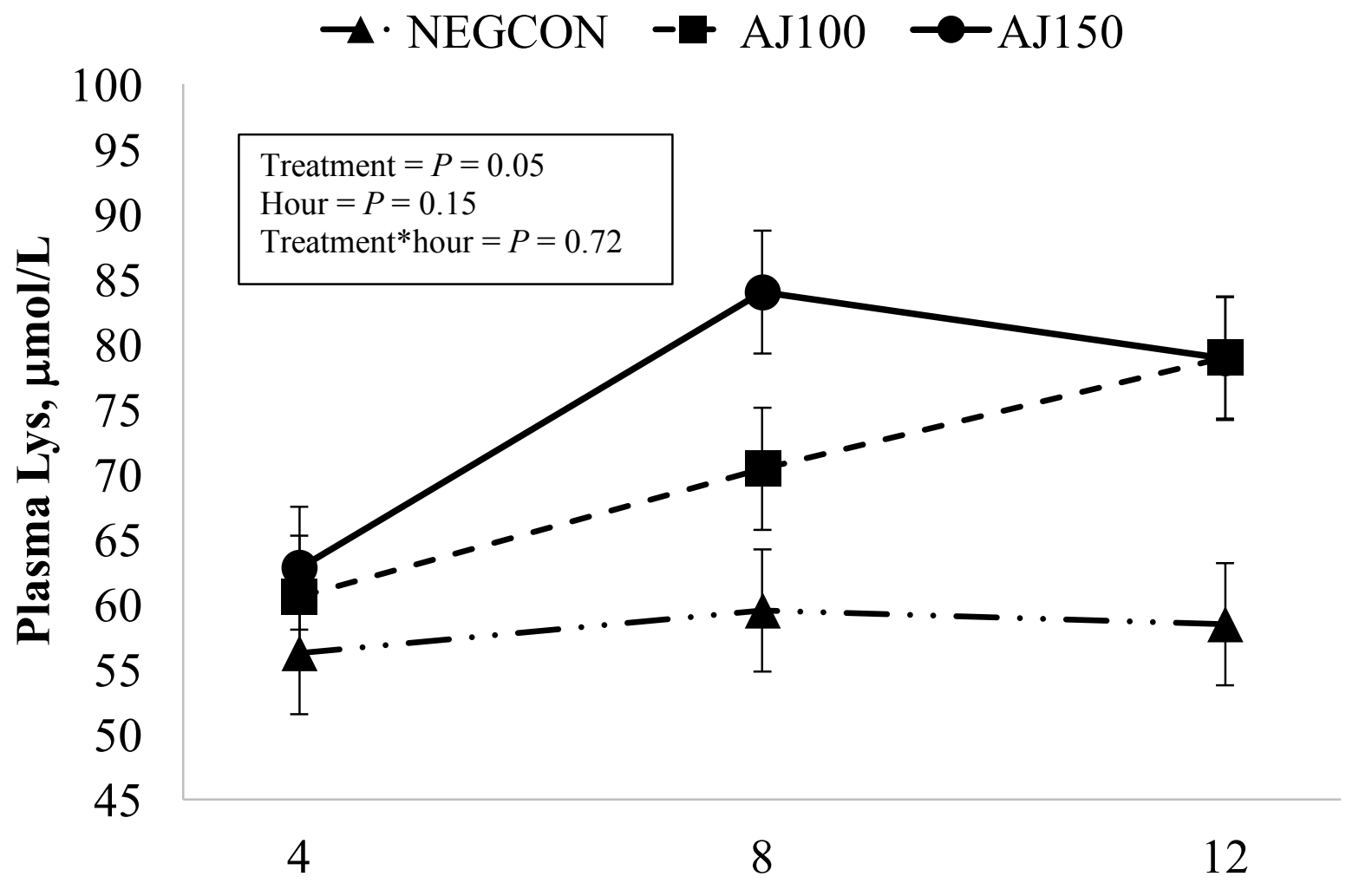

\section{Hours post-feeding}

Figure 2.2. Effect of rumen-protected Lys supplementation on cannulated steer plasma Lys

concentrations at 4, 8 and 12 h post-feeding. Main effect of treatment was significant $(P=0.05)$; main effect of hour $(P=0.15)$ and treatment*hour interaction $(P=0.72)$ were not significant. NEGCON $=$ deficient in absorbable Lys and contained no rumen-protected products; $\mathbf{A J 1 0 0}=$ formulated to balance absorbable AA to EE ratio using AminoPlus and AjiPro 3G; AJ150 = balanced to provide $150 \%$ of the absorbable Lys provided by AJ100 via increased AjiPro 3G inclusion. 


\title{
CHAPTER 3
}

\section{EFFECTS OF BALANCING FEEDLOT DIETS FOR EFFECTIVE ENERGY AND PREDICTED AMINO ACID REQUIREMENT ON STEER PERFORMANCE AND PROFITABILITY}

\begin{abstract}
The objective was to evaluate steer performance when fed diets balanced for predicted Lys requirement to effective energy $(\mathrm{EE})$ ratio using rumen-protected Lys. We hypothesized that steers consuming diets optimized for these parameters would have improved G:F and profitability (defined as when value of gain exceeds cost of gain). Crossbred steers ( $\mathrm{n}=120 ; 269 \pm 23 \mathrm{~kg}) \mathrm{were}$ used in a completely randomized design and stratified by BW and breed type. Animals were sorted into pens of 6 and fed up to 151 to $179 \mathrm{~d}$. Diets were balanced to meet EE requirement and to be adequate for non-Lys AAs. Control treatments included a negative control (NEGCON) deficient in absorbable Lys and contained no rumen-protected products; and a positive control (POSCON) where rumen-protected soybean meal (AminoPlus; AgProcessing Inc., Omaha, NE) was used to balance absorbable AA to EE ratio. Three additional dietary treatments included similar amounts of rumen-protected soybean meal and incremental amounts of rumen-protected Lys (AjiPro 3G, Ajinomoto Heartland, Inc.), formulated to provide 50\% (AJ50), 100\% (AJ100), or 150\% (AJ150) of the absorbable Lys provided by POSCON. Starting on d 151 steers were weighed on 2 consecutive days every $14 \mathrm{~d}$ and assigned a final BW when no longer profitable. Steers remained profitable for greater days $(P=0.01)$ for NEGCON $(165.6 \pm 2.2)$, POSCON $(163.8 \pm 2.5)$, and AJ100 $(165.6 \pm 2.9)$ than AJ150 $(153.9 \pm 1.2)$. Profitability of AJ100 steers was greater $(P=0.07)$ than AJ50 (156.8 \pm 1.5 d). Profitability of NEGCON steers did not differ from POSCON, AJ50,
\end{abstract}


nor AJ100 steers. Between d 112 to 179, POSCON, AJ100, and NEGCON steers all had greater $(P=0.04)$ ADG than AJ50 and AJ150 steers. Further, NEGCON, POSCON, and AJ100 did not differ from each other $(P>0.10)$ nor did NEGCON, AJ50, and AJ150. Steers consuming POSCON had lesser $(P<0.01)$ ADG $(\mathrm{kg} / \mathrm{d})$ than all other treatments during the early finishing phase $(\mathrm{d} 75$ to 112). Between d 112 to $179, \mathrm{G}: \mathrm{F}$ was greatest $(P<0.01)$ for NEGCON, POSCON and AJ100 and the three treatments did not differ from each other. Gain:feed for POSCON was lesser $(P<$ 0.05) than all other treatments during early finishing (d 75 to 112). Additionally, AJ50 G:F was greater than POSCON $(P<0.01)$ and AJ100 $(P=0.08)$ from d 75 to 112 , but did not differ from NEGCON or AJ150. AJ100 had greater $(P=0.04)$ G:F than POSCON during early finishing. Finally, NEGCON, AJ100, and AJ150 G:F between d 75 to 112 did not differ from each other. Steer DMI $(\% \mathrm{BW})$ was greater $(P=0.10)$ for AJ150 than all other treatments across the entire feeding period (d 0 to 179). When encapsulated Lys was under or over-supplemented, finishing steers became less profitable sooner. Feed efficiency increased with use of rumen-protected products during late finishing in diets formulated to meet Lys requirement, but this did not impact overall steer performance from growing through finishing.

\section{INTRODUCTION}

Ruminants can survive on low-protein, high-forage diets due to microbial conversion of non-RUP dietary $\mathrm{N}$ to post-ruminal AA in the rumen. Growing cattle have high requirements for energy and AA because they deposit lean muscle at faster rates than non-growing animals (Byers and Rompala, 1980). The amount of post-ruminal AA supplied by microbes alone may be insufficient for growing animal requirement, particularly rapidly-growing cattle consuming highenergy feedlot diets. Growing cattle are more likely to meet energy requirements when fed a typical 
feedlot diet in comparison to forage alone but even high-concentrate diets insufficient in limiting AA will inhibit animal growth (Richardson and Hatfield, 1978).

Although the current version of Nutrient Requirements for Beef Cattle (NASEM, 2016) reports that cattle require specific AA, it still expresses protein requirements in terms of MP rather than individual AA. This can lead to $\mathrm{N}$ wastage through feeding of $\mathrm{AA}$ in excess of requirement. Excess dietary $\mathrm{N}$ is costly to (1) animals, due to the energy-dependent process of $\mathrm{N}$ recycling, (2) producers, to whom protein is the most expensive component of feed, and (3) the environment, where N excretion ultimately leads to eutrophication of water bodies (Russell et al., 1992; Place, 2016). Consequently, it is of great interest to determine ruminant AA requirement, its relationship with energy intake and methods to increase post-ruminal AA supply.

Physiological stage, sex, production potential and breed type are all factors that affect animal nutrient requirements. Because increased energy intake results in increased growth, AA requirement is ultimately dependent on energy intake (Kerley, 2016). As such, it is necessary to balance absorbable AA supply with energy intake to maximize growth. Unlike the NE system, the effective energy (EE) system proposed by Emmans (1994) accounts for the different accretion rates of protein and lipid accretion in growing cattle. Research at University of Missouri has shown balancing diets for AA:EE can be more accurate in predicting feed intake than NE, where NE sometimes over-predicted energy requirement by more than $20 \%$ (Kerley, 2016).

Even if animal AA requirement is known, ensuring bypass of dietary protein is problematic due to the rumen microbiome. Most feedstuffs have some percentage of RUP, which is dependent on their percentage of CP. For decades, interest has existed to develop high-RUP feedstuffs to increase post-ruminal AA flow to the duodenum. Products developed to achieve this goal include rumen-protected soybean meal (RPSBM) and encapsulated AA. However, these products are not 
often used in beef diets, and studies reveal the post-ruminal flow of essential AA from RUP of such products is inconsistent (Ipharraguerre and Clark, 2005).

Encapsulated AA products consist of a purified core of a single AA, such as Lys or Met, surrounded by a protective coating. The purified AA are typically developed industrially via massscale bacterial fermentation. The coating of encapsulated products, which can be made from plant proteins, lipids, polysaccharides, or synthetic polymers, should allow the product to pass through the rumen without being degraded by microbes (Blaine, 2014). As a result, the film should lose its integrity when exposed to the low $\mathrm{pH}$ of the abomasum, leaving the purified AA to be absorbed by the small intestine. If protection is successful, encapsulated products can help ameliorate energy or AA imbalances in cattle (Veira et al., 1991), improve G:F (Klemesrud et al., 2000a) and maximize post-absorptive $\mathrm{N}$ efficiency (Apelo et al., 2014a).

Lysine is typically a limiting AA in grain-based diets, therefore care should be taken to ensure animals consuming high-concentrate diets receive adequate post-ruminal Lys (Richardson and Hatfield, 1978). The objective of this study was to evaluate steer performance when fed diets balanced for predicted Lys requirement to EE ratio using rumen-protected Lys. We hypothesized that steers consuming a diet optimized for EE which met predicted Lys requirement through supplementation of rumen-protected products would have improved feed efficiency, gain, and profitability (defined as when value of gain exceeds cost of gain) than steers consuming diets formulated below or above predicted Lys requirement.

\section{MATERIALS AND METHODS}

The University of Missouri Animal Care and Use Committee approved experimental animal use and protocol. One-hundred twenty steers (entry BW $=232 \pm 24 \mathrm{~kg}$ ) were purchased from a Missouri sale barn and shipped to University of Missouri Beef Research and Teaching 
Facility. Upon arrival, steers were given $24 \mathrm{~h}$ to rest and adjust to new surroundings before tagging and vaccinating. All steers were then treated with an intranasal dose of Inforce 3 (Zoetis, Florham Park, NJ) for BRSV prevention, an intramuscular vaccine (ENDOVAC-Beef, Immvac, Columbia, MO) to protect against gram negative septicemic disease, a subcutaneous dose of Bovi-Shield GOLD BVD (Zoetis, Florham Park, NJ) to vaccinate against BVD, a subcutaneous dose of Exceed (Zoetis, Florham Park, NJ) to aid in BRD prevention and an oral dose of Safeguard (Merck Animal Health, Summit, NJ) as an anthelmintic. Calves were fitted with a farm ID tag in the right ear and an electronic ID (EID, Allflex US Inc., Dallas-Fort Worth Airport, TX) in the left ear, which was used to communicate individual calf intake to the GrowSafe system (GrowSafe Systems Ltd., Airdrie, AB, Canada.) After a $21 \mathrm{~d}$ receiving period, animals were weighed and administered booster shots for BVD and IBR (Bovi-Shield Gold 5, Zoetis, Florham Park NJ), gram negative pathogens (ENDOVAC-Beef, Immvac, Columbia, MO) and clostridial infections (Vision 7, Merck Animal Health, Summit, NJ). The following day (d 0) calves were weighed again, implanted (Component IS, Elanco Animal Health, Greenfield, IN), stratified by weight and breed type, and sorted into pens of six after assignments to one of five treatments ( 5 pens/treatment). Weights from these two days were averaged to establish individual initial BW (IBW; $269 \pm 23$ $\mathrm{kg}$ ). Each pen had one automatic waterer (Ritchie Industries Inc., Conrad, IA) and one GrowSafe bunk which allowed animals ad libitum access to water and feed. The open-air pens had concrete floors and complete overhead coverage by metal roofs. Concrete floors were cleaned and bedded with sand or mulch approximately every $7 \mathrm{~d}$. Calves were fed once per day via a truck-mounted mixer (Reel Auggie 3120, KUHN North America Inc., Bordhead, WI). Cattle were weighed again on $\mathrm{d} 28,56,75$ and 112 . 
Treatments were balanced to meet vitamin and mineral requirements (NASEM, 2016), EE requirements (Emmans, 1994), RDN and RDP requirements (Russell et al., 1992) and not be limited by non-Lys AA (Table 3.1). Control treatments included a negative control (NEGCON) deficient in absorbable Lys and contained no rumen-protected products; a positive control (POSCON) where RPSBM (AminoPlus, AgProcessing, Inc., Omaha, NE) was used to balance absorbable AA to EE ratio. Three additional dietary treatments were fed each with similar amounts of RPSBM and incremental amounts of rumen-protected Lys (AjiPro 3G, Ajinomoto Heartland, Inc.) formulated to provide 50\% (AJ50), 100\% (AJ100) or 150\% (AJ150) of the absorbable Lys provided by POSCON. Rumen-protected Lys in AJ50, AJ100 and AJ150 was formulated to provide 9,18 , and $36 \mathrm{~g} / \mathrm{d}$ to each animal, respectively.

Supplement was blended at the University of Missouri Feed Mill. Ground corn served as the carrier for salt, vitamin $\mathrm{E}, \mathrm{MgO}$, vitamin $\mathrm{ADE}$ blend, rumen modifier (Rumensin 90, Elanco Animal Health, Greenfield, IN), and vitamin/mineral premix. For encapsulated Lys treatments, AjiPro 3G was also blended into the supplement. Supplements were prepared in $909 \mathrm{~kg}$ loads and stored on the farm in separate bins, where they were mixed with all other dietary ingredients immediately before feeding.

Oatlage DM was calculated weekly from samples collected via a drill-operated bale sampler. This was done to account for variable oatlage DM. The delivery of other feed ingredients was consequently adjusted weekly to ensure consistent DM \% of each ingredient was being fed. Feed samples were collected each week as feed was being dispensed into GrowSafe bunks. Approximately $0.5 \mathrm{~kg}$ from every other bunk was collected. Samples were dried at $55^{\circ} \mathrm{C}$, then ground to pass through a $2-\mathrm{mm}$ screen. A representative amount from each weekly feed sample was composited into 4 wk samples. Each 4 wk sample was analyzed for DM, OM, N content (vario 
Micro Cube, Elementar Americas, Mt Laurel, NJ), and fiber content (ANKOM ${ }^{200}$ Fiber Analyzer, ANKOM Technology, Macedon, NY). A representative amount of each 4 wk sample was composited into one overall sample per treatment and sent to University of Missouri Experiment Station Chemistry Laboratory for total AA analysis (AOAC, 2005).

Individual steer intake was monitored daily by trained personnel. Intake data were analyzed from GrowSafe between $\mathrm{d} 0$ to $75, \mathrm{~d} 75$ to $112, \mathrm{~d} 0$ to $\mathrm{d} 112$, $\mathrm{d} 112$ to $151, \mathrm{~d} 112$ to 179 and $\mathrm{d} 0$ to 179 and were adjusted for DM as analyzed from weekly feed samples. Assigned feed disappearance (AFD; percentage of feed removed from total daily feed supply traceable to calf EIDs) and assigned feed supply (AFS; percentage of total feed supply traceable to calf EIDs) were monitored for each pen. Daily feed intakes were omitted for the entire pen if the system could only account for $<85 \%$ of feed suppled to the bunk (AFS) or $<90 \%$ of corresponding feed assigned to an individual EID (AFD).

Starting on d 151, cattle were weighed on two consecutive days every $14 \mathrm{~d}$ to establish final BW (FBW) and to determine cost of gain (COG) and value of gain (VOG). Animals were designated to be harvested when calculated to be no longer profitable (when COG exceeded VOG) and when enough unprofitable animals could fill a truckload (maximum weight approximately $18,100 \mathrm{~kg})$. Profitability was calculated as:

Profitability $=[A D G$ since $1112 *$ current live cattle price/cwt $*$ predicted $\%$ retail product $]-[($ intake/d since $d 112 *$ feed cost $/ d)+$ yardage/d].

Final BW were determined on d 151, d 165 and d 179 which resulted in three harvest groups. The first group consisted of 44 steers, the second group of 42 steers and the final group of 
36 steers. One steer fell ill during the study and was administered antibiotic; he was consequently removed from the dataset due to the antibiotic withdrawal period. For the first group, 59 animals had a negative VOG:COG, but due to trucking restrictions, the bottom 15 animals (steers with the lowest VOG:COG deficit) had to wait to be shipped until the second group of cattle was ready. As a result, data was analyzed according to date at which animals became unprofitable rather than actual harvest group. Consequently, FBW, final DMI and final ADG was analyzed to include 59 animals in the first group, 28 animals in the second group and 32 animals in the final group.

\section{STATISTICAL ANAYLSIS}

The GLM procedure of SAS 9.4 (SAS Inst. Inc., Cary, NC) was used to analyze treatment differences of IBW (kg), ADG (kg/d), DMI (kg/d), DMI (\%BW), G:F and FBW (kg). Data were analyzed as a completely randomized design with steer $(n=119)$ as experimental unit. Pairwise differences were measured between treatments using the PDIFF command. Treatment results are reported as least square means with significance declared at $\alpha=0.10$.

Mean days of profitability were obtained using a time-to-event Kaplan-Meier model (the LIFETEST procedure) in SAS. Animals were organized in the model according to their FBW date (d 151, d 165 or $\mathrm{d} 179$ ) and censored in the model on d they were no longer profitable. Pairwise differences were obtained using the DIFF=ALL command. Raw $P$ values are reported.

\section{RESULTS AND DISCUSSION}

\section{Growing and finishing performance}

Performance data (Tables 3.2 and 3.3) was separated into three phases: growing (d 0 to 75), early finishing (d 75 to 112) and late finishing (d 112 to 179). Data analyzed between d 112 to 179 were calculated using FBW, final ADG and final DMI for individual steers within each 
harvest group. Each animal's FBW, final ADG and final DMI were analyzed as a complete set for periods ranging to $\mathrm{d} 179$. Day 151 was the final $\mathrm{d} \mathrm{BW}$ was measured for all steers before grouping according to profitability, so data between d 112 to 151 is also reported.

We hypothesized that feedlot steers consuming diets formulated for predicted Lys requirement and not deficient in other AA would have greater ADG compared to steers that were over- or under-supplemented Lys. This only occurred the late finishing phase (Table 3.3). A treatment effect was observed for ADG $(\mathrm{kg} / \mathrm{d})$ between d 112 to $151(P=0.04)$, where steers fed diets optimized for Lys requirement (POSCON and AJ100) had greater $(P<0.10)$ ADG than all other treatments. Between d 112 to 151, NEGCON, AJ50 and AJ150 did not differ in ADG. Between d 112 to 179 , which accounted for steers finished longer according to profitability, NEGCON, POSCON, and AJ100 steers all had greater ADG than AJ50 and AJ150 steers; further, NEGCON, POSCON, and AJ100 did not differ from each other $(P>0.10)$ nor did NEGCON, AJ50, and AJ150.

During the early finishing phase, POSCON steers had lesser $(P<0.01)$ ADG $(\mathrm{kg} / \mathrm{d})$ than all other treatments (Table 3.2; d75 to 112). This was interesting, as POSCON steers had greater ADG than all other treatments except AJ100 during late finishing (Table 3.3; d 112 to 151). However, this phenomenon balanced out between d 0 to 151 , where no main effect was observed for all treatments. It is possible that during early finishing, all treatments except POSCON were satisfying steer AA requirement. During late finishing when animal growth plateaued even more, perhaps POSCON steers experienced compensatory gain due to satisfaction of requirements during a less rapid period of growth. Growing phase ADG did not differ $(P=0.57)$ between treatments, as well as for the entire trial period ( $\mathrm{d} 0$ to $179 ; P=0.68$ ). 
We also postulated that G:F would improve in steers fed POSCON and AJ100. Indeed, a main effect of treatment was observed for G:F during late finishing phase periods of $\mathrm{d} 112$ to 151 and d 112 to 179 ( $P<0.01$ for both periods). Between d 112 to 151 , when all steers were still on trial, POSCON had greater G:F than all other treatments but did not differ from AJ100. AJ100 had a greater G:F than AJ150, but did not differ from NEGCON or AJ50. Further, NEGCON and AJ50 did not differ from AJ150. Between d 112 to 179, when groups of steers began to be shipped according to unprofitability, G:F was greatest $(P<0.01)$ for NEGCON, POSCON, and AJ100 and the three treatments did not differ from each other. NEGCON G:F was greater than AJ150, and AJ50 was intermediate between these two treatments between d 112 to 179 .

As previously mentioned, POSCON yielded lesser ADG than all other treatments between d 75 to 112 . This directly impacted POSCON G:F, which was lesser $(P<0.01)$ than all other treatments during early finishing. Further, AJ50 cattle had the greatest early finishing G:F of all treatments, stemming from numerically greater ADG and numerically lesser DMI $(\mathrm{kg} / \mathrm{d})$ during this time period. NEGCON, AJ100, and AJ150, which did not differ from each other, had greater G:F than POSCON during early finishing.

Klemesrud et al (2000b) saw increased ADG and G:F in the presence of rumen-protected AA (RPAA) in several studies where steers were fed diets based on the NRC's estimated requirements for MP and other AA (2.0 Met and 6.4 Lys, \%MP). However, treatment responses were limited to the growing phase. In one study, nine treatments containing rumen-protected Lys (RPLys) and rumen-protected Met (RPMet) were formulated to provide incremental levels of Lys from RPLys $(0,1,2,3,4,5,6,8,10$, and $12 \mathrm{~g} / \mathrm{d})$ or RPMet alone. Steer ADG and G:F was greater during the first $56 \mathrm{~d}$ in cattle supplemented 3 and $4 \mathrm{~g} / \mathrm{d}$ of Lys, but this improvement did not carry through the remainder of the feeding period. In a follow-up study, steers fed a meat and bone meal 
+ RPMet to provide 6 incremental levels of RPMet $(0,0.45,0.9,1.35,3.0$, or $6.0 \mathrm{~g} / \mathrm{d})$ had improved ADG compared to steers fed a urea-supplemented control. The advantage in ADG plateaued at 2.9 $\mathrm{g} / \mathrm{d}$ of Met. In yet another trial, steers fed a corn gluten meal supplement with incremental amounts of rumen-protected Lys $(0,1,2,3,4,5,6,8$, or $10 \mathrm{~g} / \mathrm{d}$ RPLys $)$ had greater ADG and G:F compared to steers fed a urea-supplemental control, plateauing at $0.9 \mathrm{~g} / \mathrm{d}$ Lys (Klemesrud et al., 2000a).

In an earlier growth study by the same authors, steers were fed a urea-supplemented control, meat and bone meal supplement, meat and bone meal + RPMet, or meat and bone meal + RPMet and Lys for $84 \mathrm{~d}$. The diets were not based on predicted AA requirements, but rather protein sources were fed to supply $30,40,50$ or $60 \%$ of the supplemental CP with urea supplying the remainder. This resulted in all diets containing a very low amount of CP (10.7\% DMB). Steers supplemented with RPMet had greater ADG and G:F than the urea control and meat and bone meal alone; the addition of RPLys only improved ADG and G:F in comparison to the urea control, indicating Lys was not limiting in meat and bone meal but Met was (Klemesrud et al., 1997).

Studies in which RPAA were fed to beef cattle are few and far between, likely due to dietary formulation for MP rather than essential AA requirement. Experiments in which RUP or AA were very clearly deficient revealed beneficial responses to rumen-protected products (Veira et al., 1991; Klemesrud et al., 1997; Klemesrud et al., 2000a; Klemesrud et al., 2000b), whereas studies in which researchers were uncertain if control animals were AA deficient did not elicit performance responses (Hussein and Berger, 1995; Lancaster et al., 2016; Oney et al., 2016). In vitro studies conducted in our lab (Masiero et al, unpublished data) revealed that AminoPlus actually had $38.0 \%$ RUP instead of the $72.0 \%$ reported by the product manufacturer. This may account for the variable performance data seen in POSCON steers, and because AjiPro treatments 
also contained AminoPlus, this may have had an impact on the bypass value of the AA in those treatments as well.

Steer DMI $(\% \mathrm{BW})$ was greater $(P=0.10)$ for AJ150 than all other treatments across the entire feeding period ( $\mathrm{d} 0-179)$, but was not different $(P=0.30)$ from d 0 to 151 . The difference seen between d 0 to 151 and d 0 to 179 likely stems from a large portion of AJ150 calves $(\mathrm{n}=$ 18/24) shipped on d 151 . AJ150 calves showed numerically greater DMI (kg/d) throughout growing and both finishing periods, while ADG remained relatively similar to other treatments. This resulted in a greater number of calves becoming unprofitable, and therefore shipped with the first group.

It is well-known that Lys and Arg have antagonistic effects. The exact mechanism behind this phenomenon is not well-understood. However, the only way to reverse it is by supplementing the diet with the AA that is being antagonized. The interference has reported to cause decreased growth in animals, but this was not the case in the present study. Instead, it appears steers overconsuming Lys in AJ150 consumed more feed to compensate for metabolic competition between excess dietary AA (Ball et al., 2007).

Body weights or DMI $(\mathrm{kg} / \mathrm{d})$ did not differ between treatments $(P>0.10)$ at any given time point. Additionally, no differences between ADG occurred before d $112(P=0.35)$ or across the entire feeding period $(P=0.68)$. No differences in DMI $(\% \mathrm{BW})$ were evident during the growing phase (d 0 to $112 ; P=0.31)$ early finishing $(P=0.52)$, or late finishing $(P=0.15)$, although AJ150 DMI $(\% \mathrm{BW})$ was greater $(P=0.10)$ than all other treatments for the combined 0 to $179 \mathrm{~d}$.

\section{Profitability calculations}

Value of gain and COG are dependent on volatile cattle and commodity prices, so setting an endpoint for cattle according to these calculations will vary according to market prices. 
However, COG and VOG are related to feed efficiency, as DMI and ADG are factored into their calculations. As such, we believed using the ratio of VOG:COG reflected steer efficiency while simultaneously maximizing profitability in a feedlot setting.

We set three FBW endpoints for steers on d 151, d 165 and d 179. Three groups of cattle were shipped for harvest according to negative VOG:COG, however, we had to wait to ship cattle until we could fill a pot load. As a result, the three endpoints set for cattle are not precise values of the exact point at which they crossed the unprofitability threshold.

Steers remained profitable for greater days (Figure 3.1; $P=0.01)$ for NEGCON $(165.5 \pm$ 2.2), POSCON $163.8 \pm 2.5)$, and AJ100 (165.6 \pm 2.9$)$ than AJ150 (153.9 \pm 1.2$)$. AJ100 profitability was greater $(P=0.07)$ than AJ50 $(156.8 \pm 1.5 \mathrm{~d})$. NEGCON profitability did not differ from POSCON, AJ50 nor AJ100. As previously mentioned, VOG:COG is related to feed efficiency. Consequently, these results mirror our late finishing phase observations, where NEGCON, POSON, and AJ100 had the greatest G:F. AJ150 steers, which had the least favorable G:F, were marketed in greater numbers on the first endpoint, and only two AJ150 steers remained by d 179 . By using VOG:COG as an endpoint, we were able to factor both biological and economical means by which to determine animal efficiency. Because no differences were observed between treatments for growing and early finishing in these cattle, using profitability as an endpoint gave an idea of whether there were applicable benefits to balancing feedlot diets for limiting AA.

\section{CONCLUSION}

The use of either RPSBM or encapsulated AA did not have an overall effect on steer performance throughout the entire feeding period. When partitioned into growing, and early and late finishing phases, effects of these products could be observed. POSCON steers, which 
consumed RPSBM, actually had poorer performance during early finishing than treatments that were unbalanced for AA:EE. However, during late finishing, POSCON animals experienced greater ADG and G:F than other treatments (except for AJ100). This may indicate less bypass of the product than originally anticipated, which resulted in unmet AA requirements and consequently, poorer feed efficiency during early finishing. During late finishing, when animal growth slowed and AA:EE requirements were lesser, is possible that steers consuming diets where RPSBM was the primary source of bypass AA then experienced compensatory gain. Because all AjiPro treatments also contained RPSBM, a lack of predicted bypass from AminoPlus may have also inhibited the growth potential of animals consuming encapsulated AA. When AjiPro was over-supplemented (AJ150), cattle consumed more as a percentage of their total BW, but experienced poorer feed efficiency compared to other treatments. This could indicate excess Lys competing with other AA for absorption, resulting in increased DMI to compensate for AA imbalance. Due to the fluctuation of AminoPlus' bypass value, it cannot be certain what the true balance of AA:EE was for RPSBM-containing treatments. When not under- or over-supplemented, encapsulated AA use was beneficial to using AminoPlus alone in regards to steer performance. In regards to profitability, over- or under-supplementation of RPAA was less beneficial, but AJ100 did not differ from POSCON. However, this value is related to dietary cost and not feed efficiency alone. Future research using AjiPro and other RPAA to meet predicted AA:EE requirement, while also omitting AminoPlus, would provide further insight into the true efficacy of the RPAA on steer performance. 
Table 3.1. Ingredient and chemical composition of feedlot diets.

\begin{tabular}{|c|c|c|c|c|c|}
\hline \multirow[b]{2}{*}{ Item } & \multicolumn{5}{|c|}{ Treatment $^{1}$} \\
\hline & NEGCON & POSCON & AJ50 & AJ100 & AJ150 \\
\hline \multicolumn{6}{|l|}{ Ingredient, \%DM } \\
\hline Corn & 53.3 & 52.8 & 53.0 & 53.0 & 53.0 \\
\hline DDGS & 33.4 & 20.7 & 26.0 & 25.9 & 25.7 \\
\hline AminoPlus $^{2}$ & -- & 13.3 & 7.60 & 7.60 & 7.60 \\
\hline Oatlage & 10.6 & 10.6 & 10.6 & 10.6 & 10.6 \\
\hline Lime & 1.53 & 1.53 & 1.53 & 1.53 & 1.53 \\
\hline Salt & 0.45 & 0.45 & 0.45 & 0.45 & 0.45 \\
\hline Vitamin E & 0.13 & 0.13 & 0.13 & 0.13 & 0.13 \\
\hline $\mathrm{MgO}$ & 0.26 & 0.26 & 0.26 & 0.26 & 0.26 \\
\hline $\mathrm{ADE}$ & 0.06 & 0.06 & 0.06 & 0.06 & 0.06 \\
\hline Rumensin & 0.03 & 0.03 & 0.03 & 0.03 & 0.03 \\
\hline Vitamin Mineral Premix ${ }^{3}$ & 0.19 & 0.19 & 0.19 & 0.19 & 0.19 \\
\hline AjiPro $3 G^{4}$ & -- & -- & 0.13 & 0.26 & 0.51 \\
\hline \multicolumn{6}{|l|}{ Nutritional Analysis } \\
\hline DM, \% & 73.0 & 73.0 & 73.0 & 74.0 & 73.0 \\
\hline $\mathrm{CP}, \% \mathrm{DM}$ & 16.8 & 19.5 & 18.2 & 18.2 & 18.3 \\
\hline EE Ratio* & 1.48 & 1.00 & 1.05 & 1.00 & 1.00 \\
\hline Lys Requirement, \%* & 97.0 & 100.0 & 98.0 & 100.0 & 116.0 \\
\hline
\end{tabular}

${ }^{1}$ NEGCON $=$ deficient in absorbable Lys and contained no rumen-protected products; POSCON $=$ contained rumen-protected soybean meal (AminoPlus, AgProcessing Inc., Omaha, NE) to balance absorbable AA to EE ratio; AJ50 = used AjiPro 3G (Ajinomoto Heartland Inc., Chicago, IL) to provide $50 \%$ of the absorbable Lys provided by POSCON; AJ100 = used AjiPro $3 \mathrm{G}$ to provide $100 \%$ of the absorbable Lys provided by POSCON; AJ150 = used AjiPro 3G to provide $150 \%$ of the absorbable Lys provided by POSCON.

${ }^{2} \mathrm{DDGS}=$ dried distiller's grains with solubles.

${ }^{3}$ AminoPlus (AGP, Omaha, NE) analyzed to contain $47.01 \%$ CP; 38.0\% RUP; $62.0 \%$ RDP.

${ }^{4} \mathrm{ADE}$ Nutra Mix contained 1,814,369 IU/kg vitamin A, 362,874 IU/kg vitamin $\mathrm{D}_{3}$, and $227 \mathrm{IU} / \mathrm{kg}$ vitamin E; Nutra Blend, LLC, Neosho, MO.

${ }^{5}$ Rumensin 90; Elanco Animal Health, Greenfield, IN.

${ }^{6}$ Vitamin Mineral Premix contained 1,814,369 IU/kg of vitamin A; $362,874 \mathrm{IU} / \mathrm{kg}$ of vitamin D; and $567 \mathrm{IU} / \mathrm{kg}$ of vitamin E. Contained $24.0 \% \mathrm{Ca} ; 3.0 \% \mathrm{Zn} ; 2.5 \% \mathrm{Fe} ; 2.0 \% \mathrm{Mn} ; 1.0 \% \mathrm{Cu} ; 100 \mathrm{ppm} \mathrm{Se}$; 500 ppm I; and 100 ppm Co.

${ }^{7}$ AjiPro 3G (Ajinomoto Heartland Inc., Chicago, IL) predicted to contain 50.0\% Lys-HCl. 
Table 3.2. Effects of rumen-protected lysine supplementation on growing through early finishing steer performance. *

\begin{tabular}{|c|c|c|c|c|c|c|c|}
\hline \multirow[b]{2}{*}{ Item } & \multicolumn{5}{|c|}{ Treatment $^{1}$} & \multirow[b]{2}{*}{ SEM } & \multirow[b]{2}{*}{$P$} \\
\hline & NEGCON & POSCON & AJ50 & AJ100 & AJ150 & & \\
\hline \multicolumn{8}{|l|}{$\mathrm{BW}, \mathrm{kg}$} \\
\hline IBW & 270 & 271 & 268 & 270 & 267 & 22.64 & 0.97 \\
\hline d 75 & 394 & 402 & 393 & 394 & 396 & 29.27 & 0.84 \\
\hline d 112 & 453 & 447 & 452 & 448 & 456 & 32.38 & 0.88 \\
\hline \multicolumn{8}{|l|}{$\mathrm{ADG}, \mathrm{kg}$} \\
\hline d 0 to 75 & 1.67 & 1.75 & 1.67 & 1.66 & 1.73 & 0.25 & 0.57 \\
\hline d 0 to 112 & 1.63 & 1.57 & 1.64 & 1.59 & 1.69 & 0.21 & 0.35 \\
\hline d 75 to 112 & $1.57^{\mathrm{a}}$ & $1.21^{\mathrm{b}}$ & $1.58^{\mathrm{a}}$ & $1.45^{\mathrm{a}}$ & $1.62^{\mathrm{a}}$ & 0.34 & $<0.01$ \\
\hline \multicolumn{8}{|l|}{ DMI, kg/d } \\
\hline $\mathrm{d} 0$ to $\mathrm{d} 75$ & 7.23 & 7.50 & 7.08 & 7.00 & 7.60 & 1.12 & 0.28 \\
\hline d 0 to 112 & 7.82 & 8.03 & 7.65 & 7.69 & 8.24 & 1.13 & 0.35 \\
\hline d 75 to 112 & 8.89 & 9.03 & 8.76 & 9.03 & 9.45 & 1.46 & 0.56 \\
\hline \multicolumn{8}{|l|}{ DMI, \%BW } \\
\hline d 0 to 75 & 2.15 & 2.20 & 2.12 & 2.09 & 2.27 & 0.29 & 0.23 \\
\hline d 0 to 112 & 2.17 & 2.22 & 2.14 & 2.16 & 2.30 & 0.28 & 0.31 \\
\hline d 75 to 112 & 2.09 & 2.13 & 2.07 & 2.16 & 2.22 & 0.32 & 0.52 \\
\hline \multicolumn{8}{|l|}{$\mathrm{G}: \mathrm{F}$} \\
\hline d 0 to 75 & 0.232 & 0.238 & 0.239 & 0.239 & 0.231 & 0.04 & 0.91 \\
\hline d 0 to 112 & 0.211 & 0.200 & 0.218 & 0.209 & 0.208 & 0.03 & 0.41 \\
\hline d 75 to 112 & $0.179^{\mathrm{ab}}$ & $0.137^{\mathrm{c}}$ & $0.185^{\mathrm{a}}$ & $0.163^{b}$ & $0.172^{\mathrm{ab}}$ & 0.04 & $<0.01$ \\
\hline
\end{tabular}

${ }^{\mathrm{a}, \mathrm{b}, \mathrm{c}}$ Rows with uncommon superscripts differ $P<0.10$.

${ }^{*}$ Growing phase designated as d0-d75 and early finishing phase designated as d75-d112.

${ }^{1}$ NEGCON = deficient in absorbable Lys and contained no rumen-protected products; POSCON $=$ contained rumen-protected soybean meal (AminoPlus, AgProcessing Inc., Omaha, NE) to balance absorbable AA to EE ratio; AJ50 = used AjiPro 3G (Ajinomoto Heartland Inc., Chicago, IL) to provide $50 \%$ of the absorbable Lys provided by POSCON; AJ100 = used AjiPro 3G to provide $100 \%$ of the absorbable Lys provided by POSCON; AJ150 = used AjiPro 3G to provide $150 \%$ of the absorbable Lys provided by POSCON. 
Table 3.3. Effects of rumen-protected lysine supplementation on early finishing through late finishing steer performance. *

\begin{tabular}{|c|c|c|c|c|c|c|c|}
\hline \multirow[b]{2}{*}{ Item } & \multicolumn{5}{|c|}{ Treatment $^{1}$} & \multirow[b]{2}{*}{ SEM } & \multirow[b]{2}{*}{$P$} \\
\hline & NEGCON & POSCON & AJ50 & AJ100 & AJ150 & & \\
\hline \multicolumn{8}{|l|}{$\mathrm{BW}, \mathrm{kg}$} \\
\hline d 75 & 394 & 402 & 393 & 394 & 396 & 29.27 & 0.84 \\
\hline d 112 & 453 & 447 & 452 & 448 & 456 & 32.38 & 0.88 \\
\hline d 151 & 504 & 508 & 504 & 507 & 505 & 36.87 & 0.99 \\
\hline $\mathrm{FBW}^{+}$ & 516 & 518 & 508 & 520 & 508 & 41.21 & 0.77 \\
\hline \multicolumn{8}{|l|}{$\mathrm{ADG}, \mathrm{kg}$} \\
\hline d 0 to 151 & 1.55 & 1.57 & 1.56 & 1.57 & 1.58 & 0.18 & 0.98 \\
\hline d 0 to $\mathrm{FBW}^{+}$ & 1.48 & 1.51 & 1.51 & 1.51 & 1.56 & 0.17 & 0.68 \\
\hline d 75 to 151 & 1.43 & 1.38 & 1.45 & 1.49 & 1.43 & 0.25 & 0.73 \\
\hline d 75 to $\mathrm{FBW}^{+}$ & 1.16 & 1.12 & 1.10 & 1.22 & 1.08 & 0.28 & 0.46 \\
\hline d 112 to 151 & $1.30^{\mathrm{b}}$ & $1.55^{\mathrm{a}}$ & $1.32^{\mathrm{b}}$ & $1.52^{\mathrm{a}}$ & $1.27^{\mathrm{b}}$ & 0.40 & 0.04 \\
\hline d 112 to $\mathrm{FBW}^{+}$ & $0.94^{\mathrm{ab}}$ & $1.07^{\mathrm{a}}$ & $0.84^{\mathrm{b}}$ & $1.07^{\mathrm{a}}$ & $0.79^{\mathrm{b}}$ & 0.40 & 0.04 \\
\hline \multicolumn{8}{|l|}{ DMI, kg/d } \\
\hline d 0 to 151 & 8.22 & 8.40 & 8.14 & 8.29 & 8.74 & 1.15 & 0.41 \\
\hline d 0 to $\mathrm{FBW}^{+}$ & 8.25 & 8.45 & 8.17 & 8.30 & 8.72 & 1.12 & 0.48 \\
\hline d 75 to 151 & 9.08 & 9.21 & 9.16 & 9.50 & 9.78 & 1.42 & 0.43 \\
\hline d 75 to $\mathrm{FBW}^{+}$ & 9.10 & 9.23 & 9.18 & 9.52 & 9.79 & 1.46 & 0.45 \\
\hline d 112 to 151 & 9.46 & 9.45 & 9.69 & 10.16 & 10.17 & 1.56 & 0.28 \\
\hline d 112 to $\mathrm{FBW}^{+}$ & 9.13 & 9.23 & 9.45 & 9.55 & 10.00 & 1.12 & 0.28 \\
\hline \multicolumn{8}{|l|}{ DMI, \%BW } \\
\hline d 0 to 151 & 2.14 & 2.17 & 2.13 & 2.18 & 2.28 & 0.26 & 0.30 \\
\hline d 0 to $\mathrm{FBW}^{+}$ & $2.05^{\mathrm{b}}$ & $2.10^{\mathrm{b}}$ & $2.09^{\mathrm{b}}$ & $2.07^{\mathrm{b}}$ & $2.24^{\mathrm{a}}$ & 0.26 & 0.10 \\
\hline d 75 to 151 & 2.01 & 2.03 & 2.03 & 2.12 & 2.16 & 0.29 & 0.30 \\
\hline d 75 to $\mathrm{FBW}^{+}$ & 1.95 & 1.97 & 2.00 & 2.05 & 2.14 & 0.28 & 0.15 \\
\hline d 112 to 151 & 1.98 & 1.98 & 2.02 & 2.13 & 2.12 & 0.28 & 0.15 \\
\hline d 112 to $\mathrm{FBW}^{+}$ & $1.86^{\mathrm{b}}$ & $1.88^{\mathrm{b}}$ & $1.95^{\mathrm{ab}}$ & $1.95^{\mathrm{ab}}$ & $2.06^{\mathrm{a}}$ & 0.27 & 0.07 \\
\hline \multicolumn{8}{|l|}{$\mathrm{G}: \mathrm{F}$} \\
\hline d 0 to 151 & 0.190 & 0.190 & 0.194 & 0.190 & 0.182 & 0.03 & 0.60 \\
\hline d 0 to $\mathrm{FBW}^{+}$ & 0.182 & 0.182 & 0.187 & 0.183 & 0.180 & 0.02 & 0.89 \\
\hline d 75 to 151 & 0.159 & 0.152 & 0.160 & 0.157 & 0.147 & 0.03 & 0.42 \\
\hline d 75 to $\mathrm{FBW}^{+}$ & 0.130 & 0.122 & 0.123 & 0.128 & 0.110 & 0.03 & 0.23 \\
\hline d 112 to 151 & $0.140^{\text {bc }}$ & $0.165^{\mathrm{a}}$ & $0.138^{b c}$ & $0.149^{\mathrm{ab}}$ & $0.124^{\mathrm{c}}$ & 0.04 & $<0.01$ \\
\hline d 112 to $\mathrm{FBW}^{+}$ & $0.104^{\mathrm{ab}}$ & $0.115^{\mathrm{a}}$ & $0.091^{\mathrm{bc}}$ & $0.113^{\mathrm{a}}$ & $0.079^{\mathrm{c}}$ & 0.04 & $<0.01$ \\
\hline
\end{tabular}

a,b,c Rows with uncommon superscripts differ $P<0.10$.

* Early finishing phase designated as d 75 to 112 and late finishing phase designated as d112 to FBW.

${ }^{+}$FBW is final body weight taken before at point of unprofitability. Data analyzed through d179 were calculated using FBW, final ADG and final DMI for individual steers within each group and analyzed as a complete set.

${ }^{1}$ NEGCON $=$ deficient in absorbable Lys and contained no rumen-protected products; POSCON $=$ contained rumen-protected soybean meal (AminoPlus, AgProcessing Inc., Omaha, NE) to balance absorbable AA to EE ratio; AJ50 = used AjiPro 3G (Ajinomoto Heartland Inc., Chicago, IL) to provide $50 \%$ of the absorbable Lys provided by POSCON; AJ100 = used AjiPro 3G to provide $100 \%$ of the absorbable Lys provided by POSCON; AJ150 = used AjiPro 3G to provide $150 \%$ of the absorbable Lys provided by POSCON. 


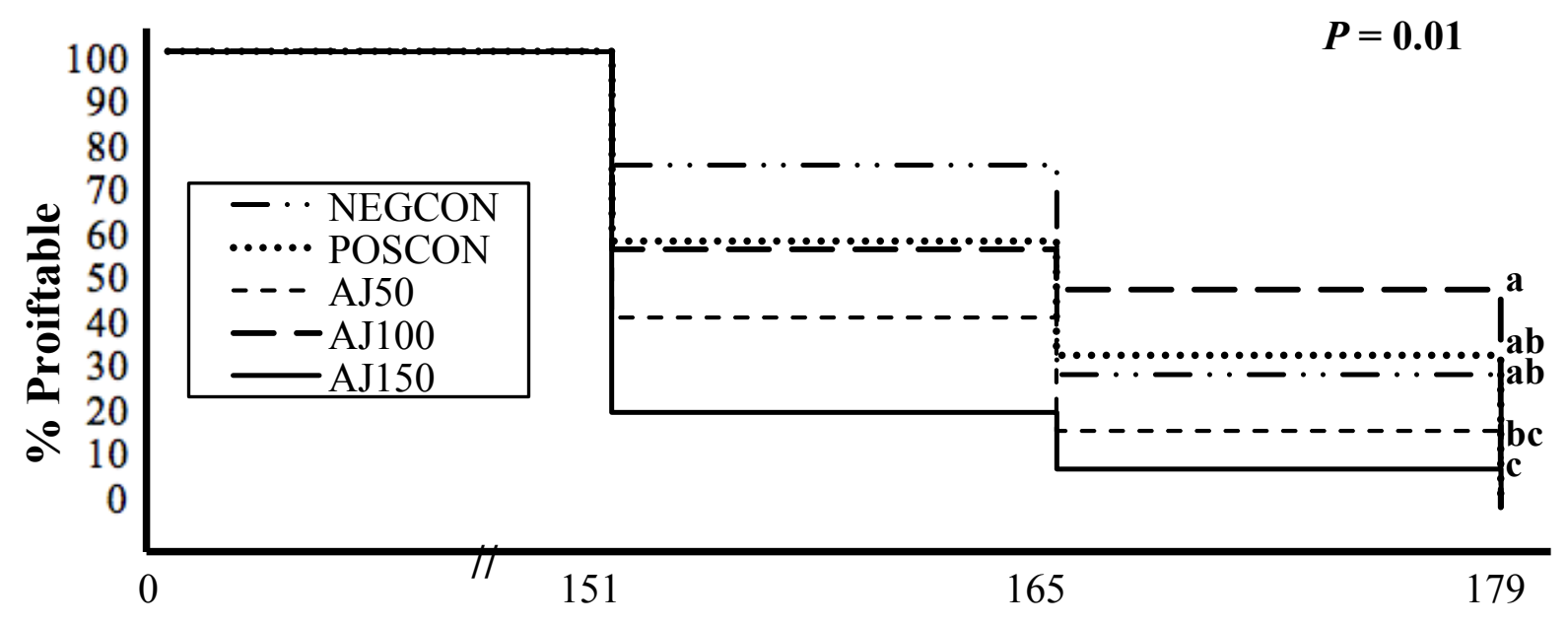

\section{Days at Final Body Weight}

Figure 3.1. Kaplan-Meier survivability plot representing percentage of steers remaining profitable after 179 days. ${ }^{\text {a,b,c }}$ means without common superscripts differ. NEGCON = deficient in absorbable Lys and contained no rumen-protected products; POSCON = contained rumenprotected soybean meal (AminoPlus, AgProcessing Inc., Omaha, NE) to balance absorbable AA to $\mathrm{EE}$ ratio; $\mathrm{AJ} 50$ = used AjiPro 3G (Ajinomoto Heartland Inc., Chicago, IL) to provide 50\% of the absorbable Lys provided by POSCON; AJ100 = used AjiPro 3G to provide $100 \%$ of the absorbable Lys provided by POSCON; AJ $150=$ used AjiPro $3 \mathrm{G}$ to provide $150 \%$ of the absorbable Lys provided by POSCON. 


\section{LITERATURE CITED}

Agarwal, U., Q. Hu, R. Baldwin, and B. Bequette. 2015. Role of rumen butyrate in regulation of nitrogen utilization and urea nitrogen kinetics in growing sheep. J. Anim. Sci. 93: 23822390.

AOAC. 2005. Official Method 982.30. 18th ed. Assoc. Off. Anal. Chem., Arlington, VA.

AOAC. 2012a. Official Method 934.01. 19th ed. Assoc. Off. Anal. Chem., Arlington, VA.

AOAC. 2012b. Official Method 942.05. 19th ed. Assoc. Off. Anal. Chem., Arlington, VA.

Apelo, S. A. et al. 2014a. Effects of reduced dietary protein and supplemental rumen-protected essential amino acids on the nitrogen efficiency of dairy cows. J. Dairy Sci. 97: 5688-5699.

Apelo, S. A., J. Knapp, and M. Hanigan. 2014b. Invited review: Current representation and future trends of predicting amino acid utilization in the lactating dairy cow. J. Dairy Sci. 97: 40004017.

Ball, R. O., K. L. Urschel, and P. B. Pencharz. 2007. Nutritional consequences of interspecies differences in arginine and lysine metabolism. J. of Nutr. 137: 1626S-1641S.

Berge, G. E., A. M. Bakke-McKellep, and E. Lied. 1999. In vitro uptake and interaction between arginine and lysine in the intestine of Atlantic salmon (Salmo salar). Aquaculture 179: 181193.

Berthiaume, R., H. Lapierre, M. Stevenson, N. Cote, and B. McBride. 2000. Comparison of the in situ and in vivo intestinal disappearance of ruminally protected methionine. J. Dairy Sci. 83: 2049-2056.

Blaine, K. L. 2014. Development of protective films for enhancing ruminal bypass of micronutrients. MS Thesis. Kansas State Univ., Manhattan.

Broderick, G., and J. Kang. 1980. Automated simultaneous determination of ammonia and total amino acids in ruminal fluid and in vitro media. J. Dairy Sci. 63: 64-75.

Brooks, M. A., R. Harvey, N. Johnson, and M. Kerley. 2012. Rumen degradable protein supply affects microbial efficiency in continuous culture and growth in steers. J. Anim. Sci. 90: 4985-4994.

Byers, F., and R. Rompala. 1980. Level of energy effects on patterns and energetic efficiency of tissue deposition in small or large mature size beef cattle. Page 141 in Energy Metabolism. Butterworth's Scientific, London.

Carder, E., and W. Weiss. 2017. Short-and longer-term effects of feeding increased metabolizable protein with or without an altered amino acid profile to dairy cows immediately postpartum. J. Dairy Sci. 100: 4528-4538. 
Chalupa, W. 1975. Rumen bypass and protection of proteins and amino acids. J. Dairy Sci. 58: $1198-1218$.

Church, D. C. 1988. The ruminant animal: digestive physiology and nutrition. Prentice Hall, Englewood Cliffs, NJ.

DeGroot, M., J. Miller, M. Arana, and E. DePeters. 2007. Variability in chemical composition and digestibility of twelve by-product feedstuffs utilized in the california dairy industry. Prof. Anim. Sci. 23: 148-163.

Do, L. D., T. L. Stevens, T. C. Kibbey, and D. A. Sabatini. 2014. Preliminary formulation development for aqueous surfactant-based soybean oil extraction. Ind. Crops and Prod. 62: 140-146.

Emmans, G. 1994. Effective energy: a concept of energy utilization applied across species. Br. J. Nutr. 71: 801-821.

Erwin, E., G. Marco, and E. Emery. 1961. Volatile fatty acid analyses of blood and rumen fluid by gas chromatography. J. Dairy Sci. 44: 1768-1771.

Fu, C. J., E. E. Felton, J. W. Lehmkuhler, and M. S. Kerley. 2001. Ruminal peptide concentration required to optimize microbial growth and efficiency. J. Anim. Sci 79: 1305-1312.

Giallongo, F. et al. 2016. Effects of rumen-protected methionine, lysine, and histidine on lactation performance of dairy cows. J. Dairy Sci. 99: 4437-4452.

Gingras, A. A. et al. 2007. Long-chain omega-3 fatty acids regulate bovine whole-body protein metabolism by promoting muscle insulin signalling to the Akt-mTOR-S6K1 pathway and insulin sensitivity. J. Physiol. 579: 269-284.

Guillaume, B., D. Otterby, M. Stern, J. Linn, and D. Johnson. 1991. Raw or Extruded Soybeans and Rumen-Protected Methionine and Lysine in Alfalfa-Based Diets for Dairy Cows1. Journal of dairy science 74: 1912-1922.

Guo, C. et al. 2017. Effects of graded removal of lysine from an intravenously infused amino acid mixture on lactation performance and mammary amino acid metabolism in lactating goats. J. Dairy Sci. 100: 4552-4564.

Hanigan, M., J. Cant, D. Weakley, and J. Beckett. 1998. An evaluation of postabsorptive protein and amino acid metabolism in the lactating dairy cow. J. Dairy Sci. 81: 3385-3401.

Haque, M. et al. 2012. Milk protein synthesis in response to the provision of an "ideal" amino acid profile at 2 levels of metabolizable protein supply in dairy cows. J. Dairy Sci. 95: 58765887.

Heitritter, G., J. Yeates, and P. Huffman. 2006. Method for manufacturing protein protected ruminant feed. US Pat. No. 5,824,355. 
Hosford, A. et al. 2015. Effects of supplemental lysine and methionine with zilpaterol hydrochloride on feedlot performance, carcass merit, and skeletal muscle fiber characteristics in finishing feedlot cattle. J. Anim. Sci. 93: 4532-4544.

Hussein, H., and L. Berger. 1995. Feedlot performance and carcass characteristics of Holstein steers as affected by source of dietary protein and level of ruminally protected lysine and methionine. J. Anim. Sci. 73: 3503-3509.

Ipharraguerre, I. R., and J. H. Clark. 2005. Impacts of the source and amount of crude protein on the intestinal supply of nitrogen fractions and performance of dairy cows. J. Dairy Sci. 88: E22-E37.

Ji, P., H. Tucker, R. Clark, M. Miura, and C. Ballard. 2016. Short communication: Effect of onfarm feeding practices on rumen protected lysine products. J. Dairy Sci. 99: 1242-1246.

Kerley, M. 2016. Opportunities to improve feed efficiency of beef production. In: 2016 Florida Ruminant Nutrition Symposium. p 34.

Kiefer, P., E. Heinzle, and C. Wittmann. 2002. Influence of glucose, fructose and sucrose as carbon sources on kinetics and stoichiometry of lysine production by Corynebacterium glutamicum. J. Ind. Microbiol. Biotechnol. 28: 338-343.

Kim, C. H., J. J. Choung, and D. G. Chamberlain. 1999. Determination of the first-limiting amino acid for milk production in dairy cows consuming a diet of grass silage and a cereal-based supplement containing feather meal. J. Sci. Food Agr. 79: 1703-1708.

Klemesrud, M., T. Klopfenstein, and A. Lewis. 1997. Addition of ruminal escape methionine and lysine to meat and bone meal. J. Anim. Sci. 75: 3301-3306.

Klemesrud, M., T. J. Klopfenstein, and A. Lewis. 2000a. Metabolize methionine and lysine requirements of growing cattle. J. Anim. Sci. 78: 199-206.

Klemesrud, M., T. J. Klopfenstein, R. Stock, A. Lewis, and D. Herold. 2000b. Effect of dietary concentration of metabolizable lysine on finishing cattle performance. J. Anim. Sci. 78: 1060-1066.

Klemesrud, M. J. 1998. Amino acid requirements for beef cattle. PhD Diss. Univ. of Nebraska., Lincoln.

Lancaster, N., J. Tekippe, M. Claeys, and J. Schoonmaker. 2016. Effect of ruminal bypass lysine on amino acid status, performance, and carcass characteristics of steers fed corn productbased diets. J. Anim. Sci 94: 778-778.

Lapierre, H., and G. Lobley. 2001. Nitrogen recycling in the ruminant: A review. J. Dairy Sci. 84: E223-E236. 
Le Boucher, J., C. Charret, C. Coudray-Lucas, J. Giboudeau, and L. Cynober. 1997. Amino acid determination in biological fluids by automated ion-exchange chromatography: performance of Hitachi L-8500A. Clin. Chem. 43: 1421-1428.

Lee, C. et al. 2012. Rumen-protected lysine, methionine, and histidine increase milk protein yield in dairy cows fed a metabolizable protein-deficient diet. J. Dairy Sci. 95: 6042-6056.

Ludden, P. A., and M. S. Kerley. 1997. Amino acid and energy interrelationships in growing beef steers: I. The effect of level of feed intake on ruminal characteristics and intestinal amino acid flows. J. Anim. Sci. 75: 2550-2560.

Mackle, T. et al. 2000. Effects of insulin and postruminal supply of protein on use of amino acids by the mammary gland for milk protein synthesis. J. Dairy Sci. 83: 93-105.

Makkar, H., and K. Becker. 1999. Purine quantification in digesta from ruminants by spectrophotometric and HPLC methods. Br. J. Nutr. 81: 107-112.

Mao, L. C., K. H. Lee, and H. F. Erbersdobler. 1993. Effects of heat treatment on lysine in soya protein. J. Sci. Food Agr. 62: 307-309.

NASEM. 2016. Nutrient requirements of beef cattle. 8th rev. ed. Natl. Acad. of Science, Engineering and Medicine, Washington, D.C.

NRC. 2001. Nutrient requirements of dairy cattle. 7th rev. ed. Natl. Acad. Press, Washington, D.C.

Oney, C. et al. 2016. Rumen protected amino acids in finishing cattle diets. Nebraska Beef Cattle Reports. Univ. of Nebraska Digital Commons, Lincoln.

Ordway, R., S. Boucher, N. Whitehouse, C. Schwab, and B. Sloan. 2009. Effects of providing two forms of supplemental methionine to periparturient Holstein dairy cows on feed intake and lactational performance. J. Dairy Sci. 92: 5154-5166.

Place, S. 2016. Environmental consequences of overfeeding protein to beef cattle. J. Anim. Sci. 95: 60-60.

Richardson, C., and E. Hatfield. 1978. The limiting amino acids in growing cattle. J. Anim. Sci. 46: $740-745$.

Roman-Garcia, Y., R. R. White, and J. L. Firkins. 2016. Meta-analysis of postruminal microbial nitrogen flows in dairy cattle. I. Derivation of equations. J. Dairy Sci. 99: 7918-7931.

Rulquin, H., and P. Pisulewski. 2000. Effects of duodenal infusion of graded amounts of His on mammary uptake and metabolism in dairy cows. J. Dairy Sci. 83: 164.

Russell, J. B. 2006. Factors affecting lysine degradation by ruminal fusobacteria. FEMS Microbiol. Ecol. 56: 18-24. 
Russell, J. B., J. D. O'Connor, D. G. Fox, P. J. Van Soest, and C. J. Sniffen. 1992. A net carbohydrate and protein system for evaluating cattle diets: I. Ruminal fermentation. J. Anim. Sci. 70: 3551-3561.

Schwab, C. G., R. S. Ordway, and N. L. Whitehouse. 2003. Amino acid balancing in the context of MP and RUP requirements. In: Proc. Four-State Appl. Dairy Nutr. Manage. Conf., Lacrosse, WI. Midwest Plan Service, Iowa State University, Ames. p 25-34.

Sibbald, I., T. Loughheed, and J. Linton. 1968. A methionine supplement for ruminants. In: Proc. Second World Conf. Anim. Prod. Univ. Maryland, College Park, MD

Slyter, L. 1990. Buffers used in the artificial rumen. In: Proc. Continuous Culture Fermenters: Frustration or Fermentation. Northeast ADSA-ASAS Regional Meeting. p 860-870.

Socha, M. et al. 2008. Extent of methionine limitation in peak-, early-, and mid-lactation dairy cows. J. Dairy Sci. 91: 1996-2010.

Tucker, H., M. Miura, I. Shinzato, and C. Ballard. 2015. Comparative bioavailability of lysine in three commercially available rumen protected lysine products using the in vivo plasma lysine response method. J. Dairy Sci. 98: 743.

USDA-ERS. 2017. Livestock, Dairy, and Poultry Outlook: January 2017, USDA-ERS.

Vaga, M., M. Hetta, and P. Huhtanen. 2016. Effects of heat treatment on protein feeds evaluated in vitro by the method of estimating utilisable crude protein at the duodenum. J. Anim. Physiol. Anim. Nutr.: 1439-0396.

Van Soest, P. J. 1994. Nutritional ecology of the ruminant. 2nd ed. Comstock Publ. Assoc., Ithaca, NY.

Vazquez-Anon, M., T. Cassidy, P. McCullough, and G. Varga. 2001. Effects of Alimet on nutrient digestibility, bacterial protein synthesis, and ruminal disappearance during continuous culture. J. Dairy Sci. 84: 159-166.

Veira, D., J. Seoane, and J. Proulx. 1991. Utilization of grass silage by growing cattle: effect of a supplement containing ruminally protected amino acids. J. Anim. Sci. 69: 4703-4709.

Virtanen, A. I. 1966. Milk production of cows on protein-free feed. Science. 153: 1603-1614.

Waggoner, J., C. Löest, C. Mathis, D. Hallford, and M. Petersen. 2009. Effects of rumen-protected methionine supplementation and bacterial lipopolysaccharide infusion on nitrogen metabolism and hormonal responses of growing beef steers. J. Anim. Sci. 87: 681-692.

Waldrip, H., R. Todd, and N. Cole. 2013. Prediction of nitrogen excretion by beef cattle: A metaanalysis. J. Anim. Sci. 91: 4290-4302.

Wallace, R. J. 1996. Ruminal microbial metabolism of peptides and amino acids. J. Nutr. 126: 1326S-1334S. 
Whitelaw, F., J. Milne, E. Ørskov, and J. Smith. 1986. The nitrogen and energy metabolism of lactating cows given abomasal infusions of casein. British journal of Nutrition 55: 537556.

Willke, T. 2014. Methionine production-a critical review. Appl. Microbiol. Biotechnol. 98: 9893-9914.

Windschitl, P., and M. Stern. 1988. Evaluation of calcium lignosulfonate-treated soybean meal as a source of rumen protected protein for dairy cattle. J. Dairy Sci. 71: 3310-3322.

Wu, S. H., and A. Papas. 1997. Rumen-stable delivery systems. Adv. Drug Deliv. Rev. 28: 323334.

Ying, F. et al. 2013. Metabolic responses to the deficiency of Lys, Arg, Met, or His in the mammary gland of lactating goats. Small Ruminant Res. 113: 219-230.

Zanton, G., G. Bowman, M. Vázquez-Añón, and L. Rode. 2014. Meta-analysis of lactation performance in dairy cows receiving supplemental dietary methionine sources or postruminal infusion of methionine. J. Dairy Sci. 97: 7085-7101. 